\title{
Quantitative Assay of Electromyograms During Mastication in Domestic Cats (Felis catus)
}

\author{
GERARD C. GORNIAK AND CARL GANS \\ Division of Biological Sciences, The University of Michigan, Ann Arbor, \\ Michigan 48109
}

\begin{abstract}
Mastication has been studied by cinematography with synchronized electromyography (computer quantified and analyzed), while unanesthetized, freely feeding cats (Felis catus) were reducing equivalent-sized chunks of raw and cooked beef and cooked chicken. Cats reduce food on one side at a time, and their chewing cycles show both horizontal and anteroposterior deflections. Food objects are shifted from side to side by lateral jerks of the head and movements of the tongue.

During the opening phase, the lower jaw is rotated relatively straight downward, and the digastric muscles are active in bilateral symmetry. Near the end of opening, the head jerks upward, both zygomaticomandibulares start to fire, and opening acceleration of the mandible decreases. Closing starts with horizontal displacement of the mandibular canines toward the working side, accompanied by asymmetrical activities from the working side deep temporalis and the balancing side medial pterygoid, as well as a downward jerk of the head. As closing proceeds, the mandibular canines remain near the working side and the working side zygomaticomandibularis and deep masseter are very active. Near the end of closing, the mandibular canine on the working side moves toward the midline, and adductors, digastrics, and lateral pterygoids of both sides are active. The adductors of the working side are generally more active than those of the balancing side.

During a reduction sequence, the number and shape of the masticatory cycles, as well as movements of the head, during a reduction sequence are affected significantly by food type. As reduction proceeds, the duration of bite and the muscular activity (as characterized by number and amplitude of spikes) change significantly among muscles of the working and balancing sides. The adductors of the working side are generally most active when cats chew raw beef, less for cooked beef, and least for cooked chicken. In general, the adductor activity reflects food consistency, whereas that of the digastrics and lateral pterygoids reflects more the vertical and lateral displacements of the mandible. Statistical analysis documents that the methods of electrode insertion and test give repeatable results for particular sites in different animals. Thus, it should be possible to compare these results with those produced while other mammals are masticating.
\end{abstract}

Much of our knowledge of the physiology of the neuromuscular system derives from work on domestic cats. Their anatomy has also been used extensively as a paradigm for that of mammals; thus generations of medical students received their first training by dissections of these animals. Cats, like other felids, are specialized terrestrial carnivores. Cranial structures characteristic of the Felidae apparently represent a single suite of adaptations for predation on vertebrates (Becht, '53; Ewer, '73;
Smith and Savage, '59; Young, '62). 'Thus, some quantitative analyses of the pattern of mastication in domestic cats seem desirable from several viewpoints.

Felids show a broad range in adult body size, though the relative proportions of their teeth, skull, and masticatory musculature are remarkably similar among Recent species (Ewer, '73; Vaughan, '72; Young, '62). Two major units of information on mastication by domestic cats are already available. In the first, jaw move- 
ments and muscular actions have been characterized on the basis of visual observations of living animals, coupled with extrapolation from anatomical characteristics and the use of mathematical models (Arendsen de Wolff-Exalto, '51; Becht, '53; Brodie, '34; Gaspard, '71; Hnik et al., '78; Ryder, 1878; Smith and Savage, '59; Turnbull,'70; van der Klaauw, '52). Chewing movements are described as generally simple, vertical, hinge, or scissor-like, with only a slight lateral component of motion. The second unit provides specific details regarding the control of masticatory cycles, in terms of jaw reflexes, proprioceptive receptors, and pathways of the central nervous system (cf. Hiiemae et al., '78; Thexton, '76). It suggests that food reduction involves rather complex interactions between the masticatory system and the food item.

In recent years, our appreciation of the complexity of functional integration has increased, as has the refinement of our technical capacity. This has allowed a shift away from an interpretation of morphology based on intuition to one based on actual measurements of movements, forces, and muscular activities. We now have analyses of the mastication of a few reptiles and representatives of several orders of mammals (cf., list in Gans et al., '78; Hiiemae, '78). Electromyograms coupled with various kinds of movement analyses now allow us to compare the changes in muscular activities that occur during reduction of different foods, that occur within chewing sequences, and that differ among mammals (de Vree and Gans, '76; Hiiemae, '78; Hiiemae et al., '78; Hiiemae and Thexton, '75; Kallen and Gans, '72; Thexton and Hiiemae, '75).

The present study reports on simultaneously recorded cinematography and electromyography from unanesthetized, freely feeding domestic cats (Felis catus, commonly $F$. domestica), ingesting equivalent-sized chunks of food, varying in consistency. Displacement records of the mandible, as indicated by the movements of the mandibular canines, were compared with electromyograms taken from standardized electrodes placed in well-defined locations. The output of such electrodes is shown here to be comparable among multiple individual test animals. The activity patterns of the major masticatory muscles, so obtained, have been converted to digital form by computer. The approach provides a basis for quantitative comparisons among muscles and among food types.

\section{MATERIALS AND METHODS}

Eight adult $(\mathrm{M}=3.6 \pm 0.3 \mathrm{~kg})$ unanesthetized, freely-feeding cats (Felis catus) were studied using electromyography (EMG) and cinematography. Ten other preserved specimens and four skulls were examined for com parison. Muscular morphology was examined in four animals freshly sacrificed for other purposes and also during autopsies of animals used for electromyography. Dissected temporomandibular joints were examined for the location of capsular ligaments and the passive limits of mandibular movements. Manipulations of the mandible were performed on three anesthetized cats prior to sacrifice.

Cats were conditioned to enter an aluminum shielded enclosure $(50 \mathrm{~cm} \times 20 \mathrm{~cm} \times 60 \mathrm{~cm})$ and to take food from a Plexiglas shelf $12 \mathrm{~cm}$ above its floor. Mirrors permitted filming the head of the animal simultaneously in frontal and lateral views.

Cats were offered cut pieces $(2 \mathrm{~cm} \times 2 \mathrm{~cm} \times 1$ $\mathrm{cm}$ ) of raw beef, cooked beef, and cooked chicken. These food types differ in texture and shear stress; clearly cooking affects the plasticity of the food (cf., Kumur et al., '78; Lister, '70; Mohsein, '70; Tuomy et al., '63). Samples of these foods were tested using a simple penetrometer (Gadd et al., '67). The mean compressive stresses were $3.04 \pm 0.32 \times 10^{2} \mathrm{~N} / \mathrm{cm}^{2}$ for raw beef, $1.93 \pm 0.43 \times 10^{2} \mathrm{~N} / \mathrm{cm}^{2}$ for cooked beef, and $1.49 \pm 0.34 \times 10^{2} \mathrm{~N} / \mathrm{cm}^{2}$ for cooked chicken. Initial trials with dry commercial cat foods and canned tuna resulted in only a few chewing cycles per food item, small displacements of the mandible, and low levels of activity from the adductor muscles. These commercial foods did not appear to tax the animals or permit comparisons of movements and muscular activities as food objects were reduced.

Ketamine hydrochloride (Vetalar), in combination with local anesthetics, was administered intramuscularly prior to all surgical procedures. All electrodes were implanted intramuscularly through small incisions in the skin. Electrodes were implanted within the temporales and masseter muscles through an incision perpendicular to the zygomatic arch, and within the digastrics and the medial and lateral pterygoid muscles through ventral incisions along the medial border of each mandibular body. Implantation to standard depth was tested on cadavers, and placement was later confirmed at autopsy. There were no significant differences in the timing or the pattern of EMG activity for the relatively restricted regions tested within each muscle (see Fig. 1 for approximate sites of electrode placement). Thus, recordings are identified only to major subdivisions of muscles. This leaves open the possibility that some differences could be demonstrated among peripheral bundles of complexly pinnate muscles, such as the masseter 

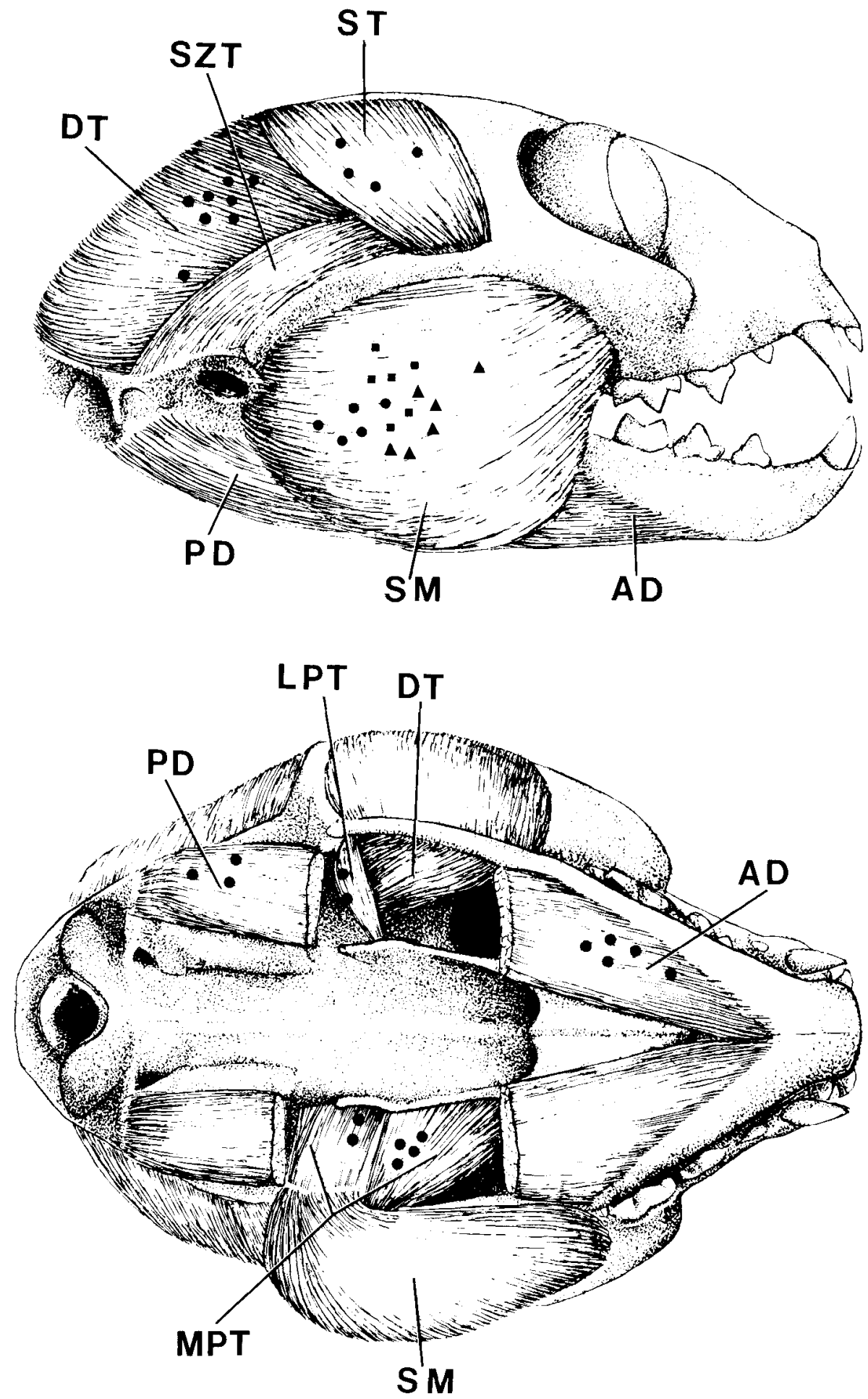

Fig. 1. F. catus. Lateral (top) and ventral (bottom) views of the masticatory musculature. The solid dots show the approximate sites of individual electrode placements in the anterior digastric (AD), deep temporalis (DT), lateral pterygoid (LPT), medial pterygoid (MPT), posterior digastric (PD), superficial masseter (SM), and the superficial temporalis (ST). The triangles show placements in the deep masseter and the squares show placements in the zygomaticomandibularis. 
(cf., Herring et al., "79; but their "masseter" is here subdivided into the superficial and deep masseters and the zygomaticomandibularis).

Bipolar electrodes made of 0.076 Tefloncoated stainless-steel wire (Medwire Corp., Mt. Vernon, NY) and $31.05 \pm 1.56 \mathrm{~cm}$ long were used for all recordings of intramuscular electrical activities. The electrodes were twisted (cf., Gorniak, '77a) and had equal bare tips, 2.16 $\pm 0.166 \mathrm{~mm}$ long for most muscles and $1.08 \pm$ $0.086 \mathrm{~mm}$ for the lateral pterygoids.

Eight (color-coded) electrodes were ordinarily implanted by 22 -gauge hypodermic needles with intradermal points during a single surgical session. Electrode wires were kinked at the incision site and then passed subdermally to the dorsum of the neck where they were soldered to a minipin connector. Recording sessions always started more than 24 hours after electrode insertion to permit the animal to recover from anesthesia and surgery. After this interval, all cats fed freely. Comparisons with control cinematography of unoperated cats revealed no obvious change in feeding behavior as a result of the surgical procedures.

Motion picture sequences were recorded on Kodak Ektachrome EF daylight film at between 32 and 64 frames per second with a Beaulieu R16 camera, using two standard movie lights. Individual frame identification was provided by recording electrical pulses triggered by the shutter mechanism of the camera. Signals from up to 12 pairs of electrodes were amplified through combinations of Tektronix 26A2 and FM 122 preamplifiers and Honeywell Accudata 117 DC amplifiers, monitored on a Brush 481 strip chart recorder and a Tektronix 565 oscilloscope, and stored for later use on a Honeywell 5600 medium bandpass 14-channel FM tape recorder.

A Layafette analytical projector was used to analyze films of movements of the mandible, tongue, and head, and to project individual film frames for plotting of chewing cycles from frontal and lateral views. Some 800 chewing cycles were analyzed, including a minimum of 100 cycles for each type of food offered. Movements of the mandible were recorded by plotting the position of the base of the lower canines with respect to the maxillary canines and the nostrils from both frontal and lateral views. Movements of the tongue were readily visible when the mouth was opening, when the mouth was wide open, and again when the mouth was closing. Although the tongue consistently protruded from the mouth at the wide-open position, one or both of the lower canines remained visible in each cycle. Despite this consistent movement by the tongue, the positions and movements of the food could be observed once the tips of the mandibular canines dropped below the level of the tips of the maxillary ones.

Displacements of the mandible and head were measured from a scale photographed at the start of each recording session. Graphs of displacements allowed plotting of interframe velocities and accelerations by graphical differentiation (cf. Kallen and Gans, '72)*. Electromyograms were analyzed on a modified Hewlett Packard 21MX minicomputer (with $32 \mathrm{~K}$ memory). Up to four EMG records were scanned simultaneously to count the number of spikes corresponding to each film frame and the mean spike amplitude for that interval. The conversion factor is $40 \mathrm{mv}$ (positive) recorded on tape/ per unit, or 11.9 units/mv (peak to peak) at the electrode tips for our amplification arrangement. Noise levels were automatically subtracted from the zone scanned. The tape was marked by the computer so that multiple scans of simultaneously recorded EMGs could be compared to each other. The significance of differences among means was tested by the Student $t$-test for significance of two sample means (Simpson et al., '60). Bar graphs of the number of spikes and their amplitudes were correlated with film records of chewing movements. Seventy reduction sequences of EMGs with good simultaneous cine were examined in detail. Data were also taken from EMG records without cine by cross-correlation among muscles.

\section{ANATOMY \\ General}

Numerous papers, manuals, and books describe the anatomy of cats; major sources exist for the consideration of the teeth, skull, and masticatory muscles (Becht, '53; Crouch, '69; Gaspard, '71; Peyer, '68; Reighard and Jennings, '35; Schumacher, ' 61 ; Taylor, '76; Turnbull, '70). Thus, the morphology of the major masticatory muscles (Fig. 1) as well as that of the skull and dentition (Fig. 2) are illustrated but not discussed here, whereas the temporomandibular joint and possible movements during manipulations of the mandible are briefly reviewed.

\section{Temporomandibular joint}

Each mandibular condyle fully fills a glenoid fossa, which lies in the zygomatic process of the

\footnotetext{
* It should be noted that the scales for the acceleration graphs given in Kallen and Gans ('72), de Vree and Gans ('76), and Gorniak ("77a) are low by a factor equivalent to the filming rate.
} 

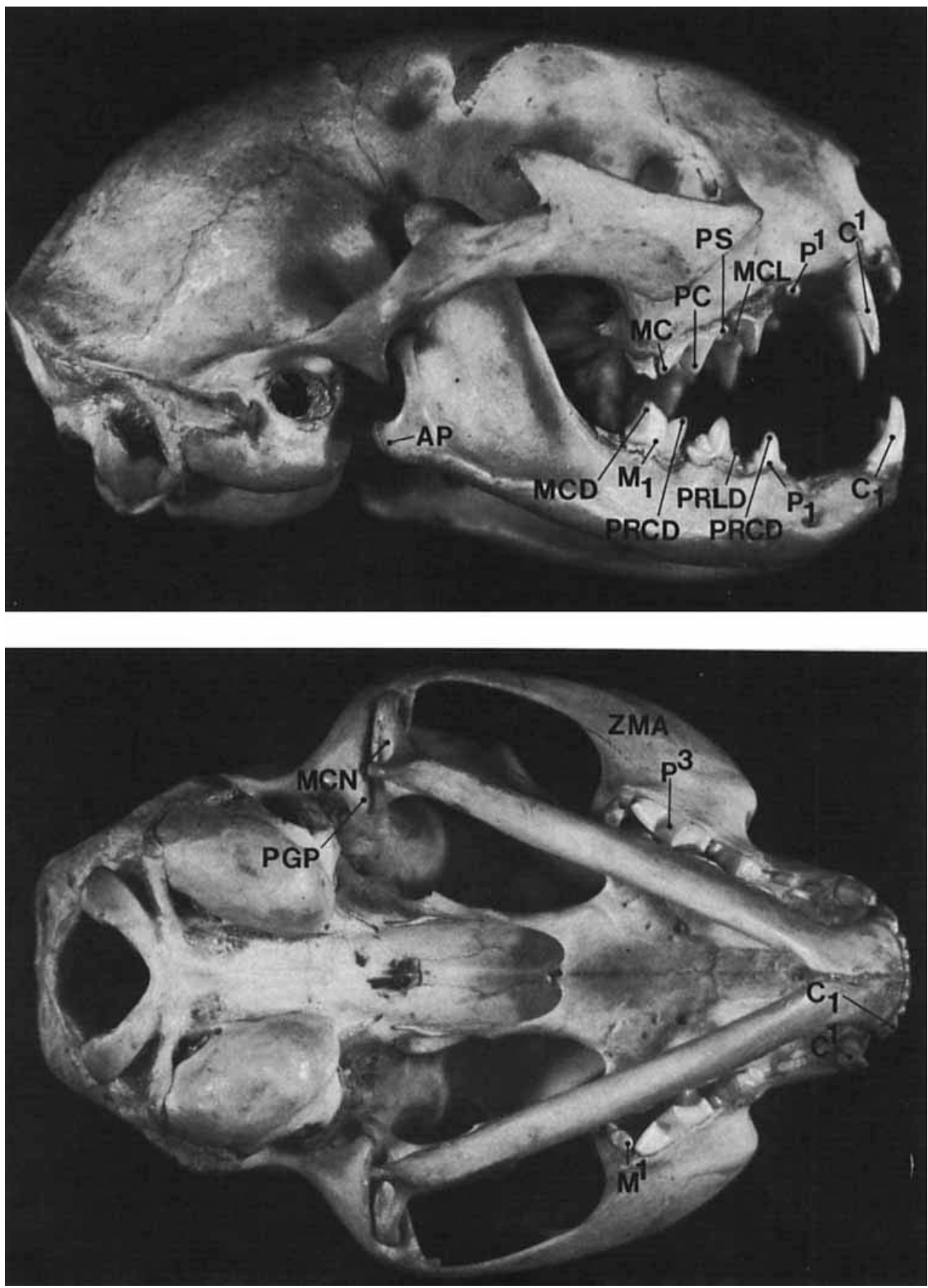

Fig. 2. F. catus. (Top) Lateral view of the skull showing the teeth, robust zygomatic arch, prominent coronoid process, and reduced angular process. (Bottom) Ventral view of the skull showing the teeth, mandibular condyles, and mandibular fossae. Note the horizontal separation of the teeth at the bottom right when the opposing tooth rows are in occlusion and the lack of bony boundaries along the medial and lateral aspects of the mandibular fossae. AP, angular process, $\mathrm{C}^{1}$, maxillary canine, $\mathrm{C}_{1}$, mandibular canine, $\mathbf{M}^{1}$, maxillary molar; $\mathbf{M}_{1}$, mandibular molar; MC, metacone; MCD, metaconid; MCL, metaconule; $\mathrm{MCN}$, mandibular condyle; $\mathbf{P}^{1}$, first maxillary premolar; $\mathbf{P}_{1}$, first mandibular premolar; $\mathbf{P}^{*}$, third maxillary premolar; PC, paracone; PS, parastyle; PGP, postglenoid process; PRCD, protoconid; PRLD, protoconulid; ZMA, zygomatic arch (Nomenclature of Osborne, cf. Kraus et al., '69). 
temporal bone. A prominent postglenoid process forms the posteromedial boundary of the fossa and a low bony ridge extends laterally to complete its posterior margin. Another low bony ridge, forming the anterior margin, is enlarged slightly at its anterolateral border. Both the medial and the lateral margins of the fossa lack bony limits that might restrict transverse condylar movements.

The posterior, medial, and lateral aspects of the capsule of the temporomandibular joint are relatively thick, but the anterior wall is quite thin. Almost the entire posterior portion of the capsule is formed by the posterior capsular ligament, which extends from the postglenoid process to the posterior aspect of the condylar neck. The medial and lateral ligaments form most of their respective capsular walls. The medial capsular ligament extends from the tympanic portion of the temporal bone just anterior to the mandibular condyle to the medial aspect of the condyle. The lateral capsular ligament extends anteriorly from the lateral border of the zygomatic process of the temporal bone to the lateral surface of the condylar neck.

An articular disc divides the joint space into distinct superior and inferior compartments and attaches peripherally to the temporomandibular joint capsule. The disc is uniform, except for slight thickening of its medial margin.

\section{Manipulations}

The mandibles may rotate around three axes and may translate slightly along three axes as well. The major rotation occurs around a transverse axis through the condyles; this is the "opening-closing" movement of the lower jaw. A secondary rotation is possible about a vertical axis through either condyle; the opposite condyle then slides anteriorly and shifts the canines toward the side about which rotation proceeds. Finally, the lower jaws may rotate longitudinally, most commonly about a line passing through the long axis of the balancing mandible when the cat encounters resistant food on one side. The balancing side then closes farther than the working side and a line connecting the bases of the mandibular canines will form an angle to that connecting the bases of the maxillary ones.

If the teeth are in full occlusion, the lower jaws can be moved only slightly along the anteroposterior and the true transverse axes and barely be rotated about a vertical axis. Anteroposterior movements of the lower jaws and their rotation about a vertical axis are limited because 1) the tips of the lower canines override the premaxillary bone and abut medially on the 3rd upper incisor; 2) the protocone of the upper carnassial interdigitates between the second mandibular premolar and lower carnassial; and 3) the metaconid of the lower carnassial articulates with the posterior buttress formed by the crown of the upper molar. Transverse movements are limited by the lower canines and upper incisors, as well as by the overlapping cutting blades of the upper and lower carnassials.

If the lower jaws are rotated open only until the tips of the lower canines lie midway along the length of the upper, anteroposterior movements remain limited at the temporomandibular joint. Transverse movements and rotation about a vertical axis remain limited by the canines and the carnassials. If the mandible is depressed until the canine tips clear each other, the mandible can move transversely.

Each temporomandibular joint permits a slight transverse and an anteroposterior (propalinal) movement of its condyle, as well as rotation about the long axis of one ramus of the lower jaw. The jaw may be translated transversely by shifting both condyles in the same horizontal direction or by rotating one condyle anterolaterally about an axis through the opposite one. In either pattern of condylar movement, the degree of transverse movement produces unilateral contact between the tips of the upper and lower canines. Asymmetric downward and lateral forces at the tips of the lower canines or at the mandibular carnassials tend to rotate the lower jaw about its long axis. Transverse movements and rotation about the long axis are limited by the medial and lateral capsular ligaments. Anteroposterior movements may shift the tips of the mandibular canines slightly beyond the anterior surfaces of the maxillary ones; however, this movement is limited by the posterior capsular ligament. Posterior shifts of the jaw are blocked by the prominent postglenoid process.

Rotation of the condyles about their long (transverse) axes completely separates the upper and lower carnassials. The downward movement (opening) is limited by tautening of the medial and lateral capsular ligaments, whereas upward movement (closing) begins to tense the posterior capsular ligament as the tips of the lower canines approach those of the uppers.

\section{MOVEMENT}

Ingestion

When cats ingest food, one observes obvious opening and closing movements of the mandi- 
ble, protrusive and retrusive movements of the tongue, and upward, forward, and sideward movements of the head; the movements reflect the size and consistency of the food.

When large chunks of meat are picked up, the tips of the canines impale the meat as the mouth closes. The mouth then opens slightly and the tongue simultaneously pushes against the lower surface of the meat, supporting it from below and gradually disengaging it from one or both lower canines. The lower jaw next opens rapidly, the tongue retrudes, and the head jerks upward and laterally. The upward movement of the head frees the meat from the upper canines, so that the retrusion of the tongue and forward movement of the head move the food posteriorly. In addition, jerks of the head toward one side shift the food inertially toward the opposite side of the mouth. The mouth then closes rapidly and the food is again caught between the teeth. When small chunks of beef (approximately $1 \mathrm{ml}$ ), tuna, and dry commercial cat food are picked up, the head jerks less and the jaws stay closer together; the food is initially caught between the incisors and shifted by protrusive and retrusive movements of the tongue.

\section{Mastication}

\section{General}

Reduction of food by cats involves complex movements of the head, jaw, and tongue. Chewing is asymmetric; there are working (active or ipsilateral) and balancing (passive or contralateral) chewing sides. Each cycle of a reduction sequence consists of an opening and a closing phase.

The reduction sequence starts after the food has been grasped. The mouth is then slightly opened, and opened further on the working side than on the balancing side. When viewed from the front (Fig. 3), the mandibular canines move relatively straight downward during the opening phase. However, at a food-specific frequency, this downward path may be interrupted by a slight, reversing, upward movement near the start of opening. The opening phase of these cycles may then be subdivided into a "slow" and a "fast" opening. When viewed from the side, each mandibular canine appears to move vertically downward at the start of the opening phase. One often notes a simultaneous anterior and dorsal displacement coincident with the reversing movements of opening. As opening proceeds, the path traced by the canine curves posteriorly.

The closing phase begins with a slight horizontal movement toward the working side. As

\section{FRONTAL VIEW} CLOSE $\uparrow$

LATERAL VIEW
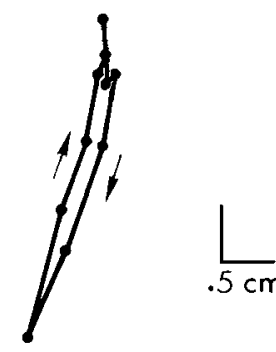

B
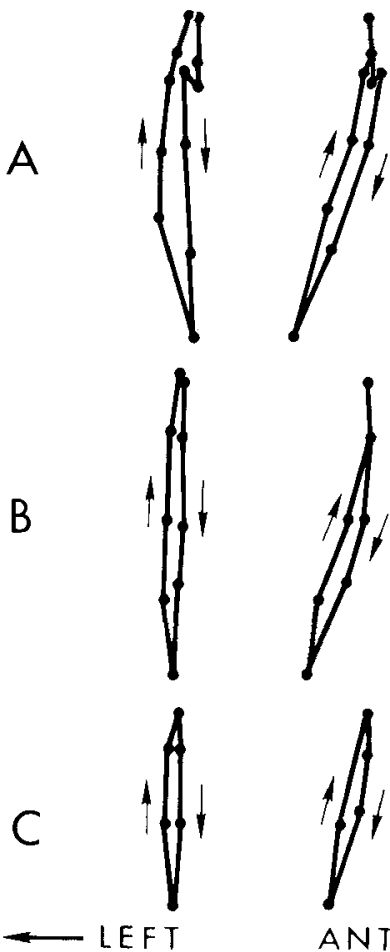

ANTERIOR $\longrightarrow$

\section{OPEN}

Fig. 3. F. catus. Representative chewing cycles showing the shifts of the left mandibular canine relative to the maxillary one in simultaneous frontal (vertical) and lateral (propalinal) views when the cat is masticating cooked beef. The working side is left. The original film from which the record is plotted was recorded at 35 frames per second. Note the changes in mandibular displacements from the start (A), to the middle (B), and the end (C) of a reduction sequence.

closing proceeds, the mandibular canine gradually reverses direction to move medially until the tip of the canine of the working side just contacts the tip of the corresponding upper canine. The mandibular canine of the working side then moves sharply toward the midline; the canine of the working side following the medial border of its upper canine. At the end of the closing phase, the teeth of each side are closest to full occlusion. If food remains between the teeth of the working side, the lower canine of the working side is lower than that on the balancing side. During the closing phase, the canine moves slightly anteriorly, and near the end of closing, rejoins and then follows the path of the opening phase until full closure. 
As the size of the food object becomes smaller and the bolus moves posteriorly between the teeth, the lower jaw gradually approaches a fully closed position at the end of each cycle and the degree of longitudinal rotation gradually decreases. While the closing jaw continues to move toward the working side, the last five to six masticatory cycles of a sequence show least lateral displacement.

Food transfer from side to side occurs by swings of the head and movements of the tongue while the mandible is depressed. The pattern of jaw movement relative to the head is not significantly affected thereby. The degree of head movement changes with food type and as the size of the food'object becomes smaller during the process of mastication.

\section{Mastication of three food types}

Cats were offered standard-sized chunks of raw beef, cooked beef, and cooked chicken. Those descriptors of the masticatory sequence that differ are noted in Table 1, while Figures 4-6 indicate sequential cycles of typical sequences.

For each of the food types studied, the reduction movements of the mandibular canines relative to the maxillary canines differ more in frontal than in lateral view. Furthermore, horizontal displacements during a closing phase are similar for the different food types; they are also similar when reversal closing occurs during the opening phase (when the cat is reducing raw and cooked beef). Consequently, only frontal views of vertical displacement, velocity, and acceleration have been illustrated (Figs. 7-9).

Graphs of vertical displacement for all food types show that the mouth remains closed for
30 to 90 msec between successive cycles. When raw (Fig. 7) and cooked beef (Fig. 8) are reduced, successive cycles are irregular; they show small and then large displacements during an opening phase. Cycles for cooked chicken (Fig. 9) are more regular. The jaws open farther when cats masticate raw and cooked beef than when they masticate chicken. Mean displacements ( $\pm 1 \mathrm{SD}$; displacements measured from the start to the end of the opening phase) for an entire sequence are $2.57 \pm 0.334 \mathrm{~cm}$ for raw beef, $2.70 \pm 0.307 \mathrm{~cm}$ for cooked beef, and 2.37 $\pm 0.224 \mathrm{~cm}$ for cooked chicken. However, as the jaws do not close fully during early cycles of a sequence, mean opening displacements for each cycle do not differ significantly among the three foods.

Maximal opening and closing velocities are similar for all food types. Opening velocity is low during initial jaw opening, when the mandibular teeth disengage from the food, and reaches maximum just before the mouth is wide open. Maximal closing velocity occurs about midway through the closing phase. Thereafter, closing velocity decreases as the teeth penetrate the food.

Maximal opening and closing accelerations for all food types decrease toward the end of a complete reduction sequence, as vertical jaw movements decrease. Within one chewing cycle, maximal opening acceleration is reached just after the tips of the upper and lower canines separate. Maximal closing acceleration occurs at the instant of reversal; acceleration then decreases rapidly as the tips of the opposing canines approach each other. Maximal closing acceleration is two to three times greater than maximal opening acceleration.

TABLE 1. Comparison of masticatory sequences of cats when fed standard-sized pieces of three distinct foods

\begin{tabular}{|c|c|c|c|c|c|}
\hline $\begin{array}{l}\text { Type of } \\
\text { food }\end{array}$ & $\begin{array}{l}\text { Rate (cycles } \\
\text { per second) }\end{array}$ & $\begin{array}{l}\text { Cycles/chunk } \\
\text { ingestion to } \\
\text { swallowing } \\
\text { (mean } \pm 1 \text { SD) }\end{array}$ & $\begin{array}{c}\text { Food } \\
\text { transfer }\end{array}$ & $\begin{array}{l}\text { Interruptions } \\
\text { and reversal } \\
\text { during opening }\end{array}$ & $\begin{array}{l}\text { Full } \\
\text { closure }\end{array}$ \\
\hline Raw beef & 3.0 & $30 \pm 4.35$ & $\begin{array}{l}1 \text { to } 2 \text { times } \\
\text { during initial } \\
3-5 \text { cycles }\end{array}$ & $\begin{array}{l}\text { Every 3rd to } 4 \text { th } \\
\text { cycle for first } \\
60-70 \% \text { of the } \\
\text { strokes, fewer } \\
\text { thereafter }\end{array}$ & $\begin{array}{l}\text { By } 20 \text { th to } \\
22 \text { nd cycle } \\
\text { cycle }\end{array}$ \\
\hline $\begin{array}{l}\text { Cooked } \\
\text { beef }\end{array}$ & 3.0 & $19 \pm 2.75$ & $\begin{array}{l}2 \text { to } 4 \text { times } \\
\text { during initial } \\
10-12 \text { cycles }\end{array}$ & $\begin{array}{l}90 \% \text { of first } \\
60-70 \% \text { of the } \\
\text { strokes, fewer } \\
\text { thereafter }\end{array}$ & $\begin{array}{l}\text { By } 16 \text { th to } \\
18 \text { th cycle }\end{array}$ \\
\hline $\begin{array}{l}\text { Cooked } \\
\text { chicken }\end{array}$ & 3.5 & $10 \pm 2.20$ & $\begin{array}{l}1 \text { to } 2 \text { times } \\
\text { during } \\
\text { initial 5-6 } \\
\text { cycles }\end{array}$ & $\begin{array}{l}\text { Rare, a } 30-60 \\
\text { msec. stop }\end{array}$ & $\begin{array}{l}\text { By } 4 \text { th to } 5 \text { th } \\
\text { cycle }\end{array}$ \\
\hline
\end{tabular}



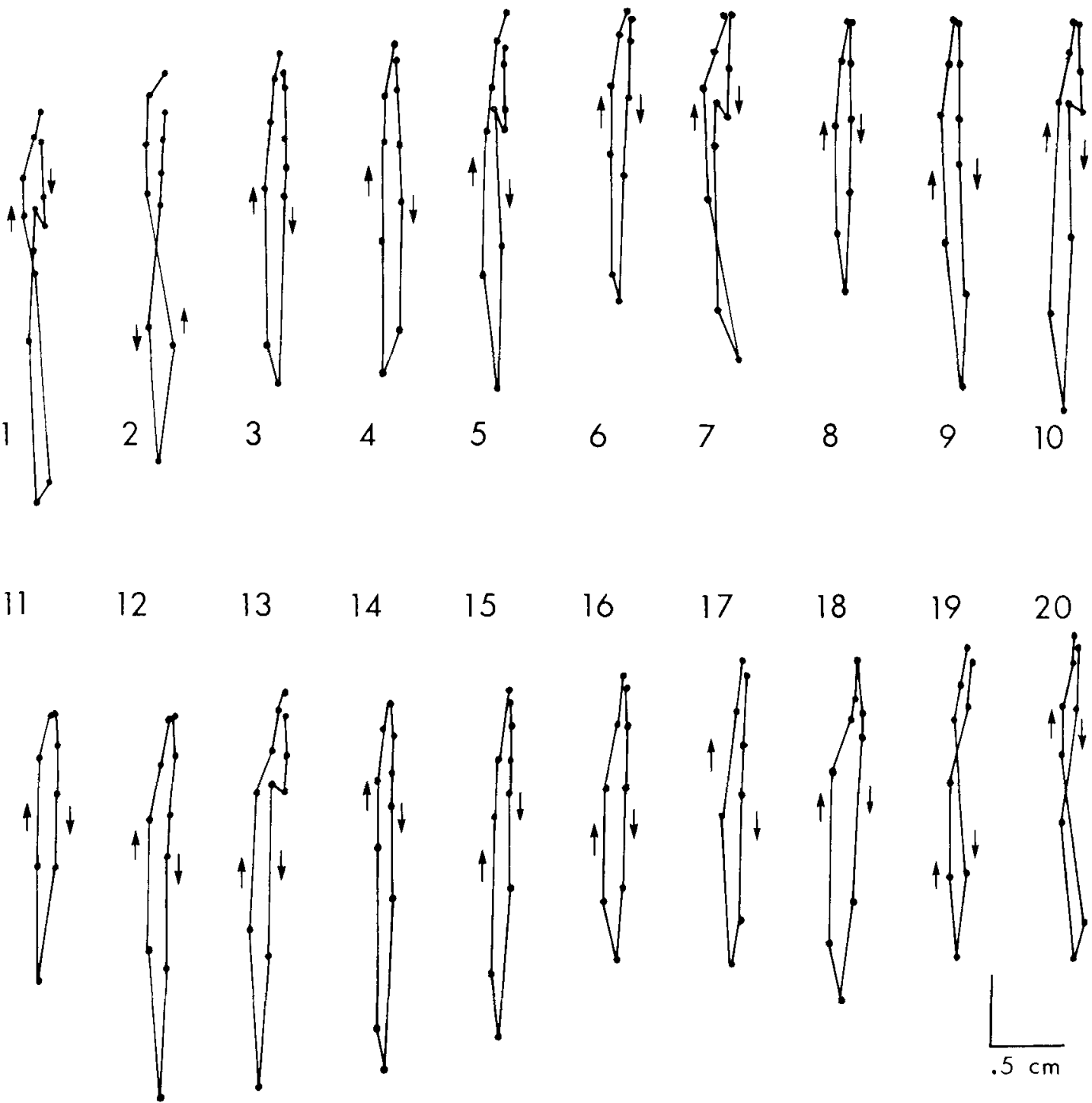

Fig. 4. F. catus. Frontal views of sequential chewing cycles showing the position of the base of the left mandibular canine (relative to the maxillary one) of a cat that is reducing raw beef. The plots show progressive changes in closing ( $\uparrow$ ) and opening (1) displacements for sequential chewing cycles. Traced from films taken at 35 frames per second. The working side is left. The numbers refer to the place of the cycle in the sequence. The first cycle shows a closing displacement during the opening phase. The reversals occur intermittently at the beginning of the sequence.

Horizontal displacements of the lower jaw are similar for the different food types. Displacement toward the working side starts with the closing phase (Fig. 10). As closing proceeds, horizontal displacement decreases gradually and the mandibular canine on the working side moves toward the midline before the mouth has closed completely. The transient closing displacements during the opening phase are ac- companied by small horizontal movements directed either toward the balancing side with reversal toward the working side or toward the working side only.

For all food types, horizontal velocities and accelerations toward the working side reach maxima at the start of the closing stroke, then decrease gradually as the jaw continues to close. Their magnitudes also decrease near the 

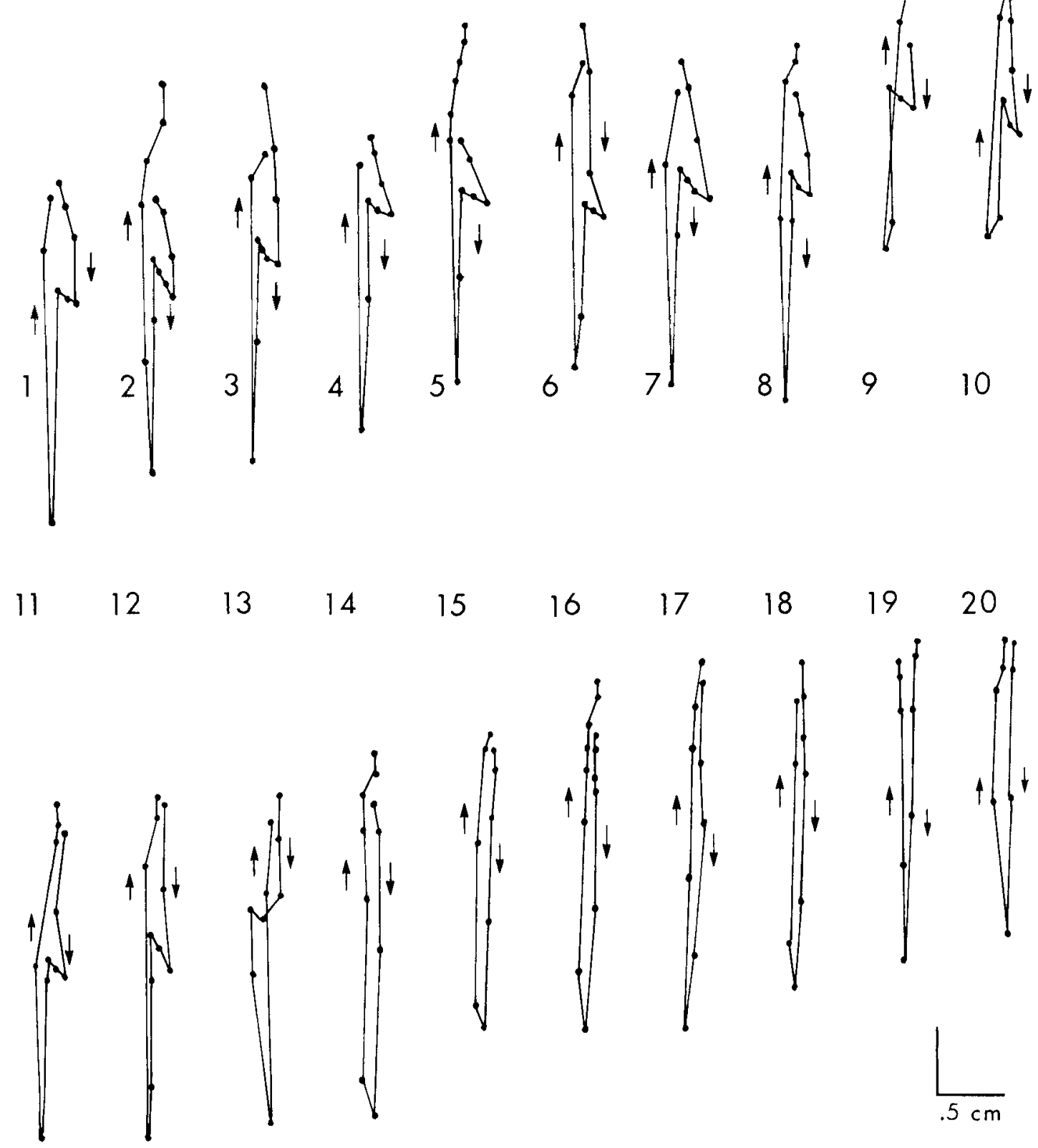

Fig. 5. F. catus. Frontal views of sequential cycles when a cat is masticating cooked beef. Conventions as in Figure 4. Progressive changes occur in the closing $(\uparrow)$ and opening $(\downarrow)$ displacements during successive chewing cycles. Reversing displacements occur regularly during the opening phase during more than the first cycles of a masticatory sequence. 


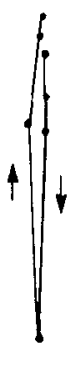

1

6

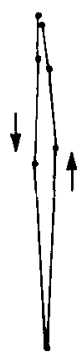

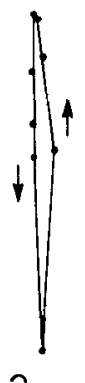

2

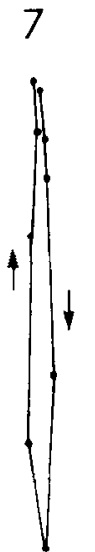

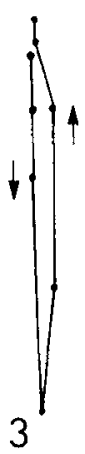
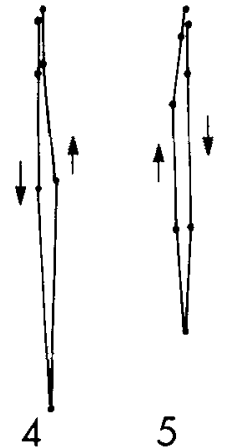

5

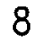

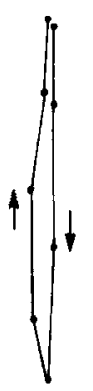

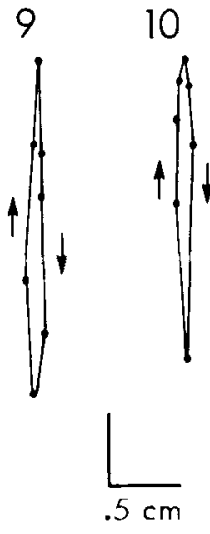

10
Fig. 6. F.catus. Frontal views of sequential cycles when a cat is masticating cooked chicken. Conventions as in Figure 4. Progressive changes occur in the closing ( $\uparrow$ ) and opening $(\downarrow)$ displacements during successive chewing cycles. Reversing displacements during the opening phase are rare. The number of chewing cycles per sequence is lower than during the reduction of equivalent-sized chunks of raw and cooked beef.

end of a reduction sequence. Although maximal horizontal displacements, velocities, and accelerations are similar for all three foods, they are much smaller than those in the vertical direction.

\section{Movements of the head}

The head moves both horizontally and vertically during mastication. Lateral movements of the head occur most frequently when cats chew cooked beef, less with chicken, and least with raw beef. Lateral movements of the head are fewest during the last half of the reduction process, as chewing then generally proceeds on one side of the mouth.
Cats tend to face the balancing side during mastication. However, the head still moves horizontally during both the opening and the closing phases of a masticatory cycle (Fig. 11). The head moves farther toward the balancing side during the opening phase and at the start of the closing phase. The head reverses direction and moves toward the working side as the teeth contact the bolus near midclosure. When food is transferred from one side of the mouth to the other, the head shifts farther toward the old working side at the end of closing; the snout then faces almost directly forward. The head next moves still farther toward the old working side during the next opening phase and continues this lateral movement at the start of closing. Concurrently, the food object is shifted to the new working side.

The head moves vertically, upward when the mouth opens and downward when it closes. Rarely does the head show dorsal movement at the start of the opening phase, although slight downward (ventral) movement of the head may accompany any interrupting reversing movements during opening. However, the head starts to move upward as the mandibles begin to accelerate sharply downward. Near the end of the opening phase, as opening acceleration of the mandible starts to decrease, the head accelerates upward and reaches its maximal upward displacement at the instant that the mouth is wide open. The head then accelerates downward as the mandible starts to close. Head movement stops at the end of the closing phase.

During jaw opening, the head moves upward and toward the balancing side. At the start of closing, the head moves downward and toward the balancing side and then reverses direction toward the working side as the canines approach each other. Vertical head movements are greatest at the start of a reduction sequence and greater for raw and cooked beef than for chicken. As the chunks of food become smaller during mastication, the amplitude of vertical head movements decreases for all food types.

\section{Movements of the tongue}

When food is transferred between the sides of the mouth, the tongue is first protruded during the opening phase and is then retruded and moved downward while the mouth is wide open. As the mouth closes, the tongue moves dorsally and somewhat laterally; it contacts the food on the balancing side. This combination of backward and dorsal movements of the tongue, coupled with lateral and sometimes forward movements of the head, will shift large food 

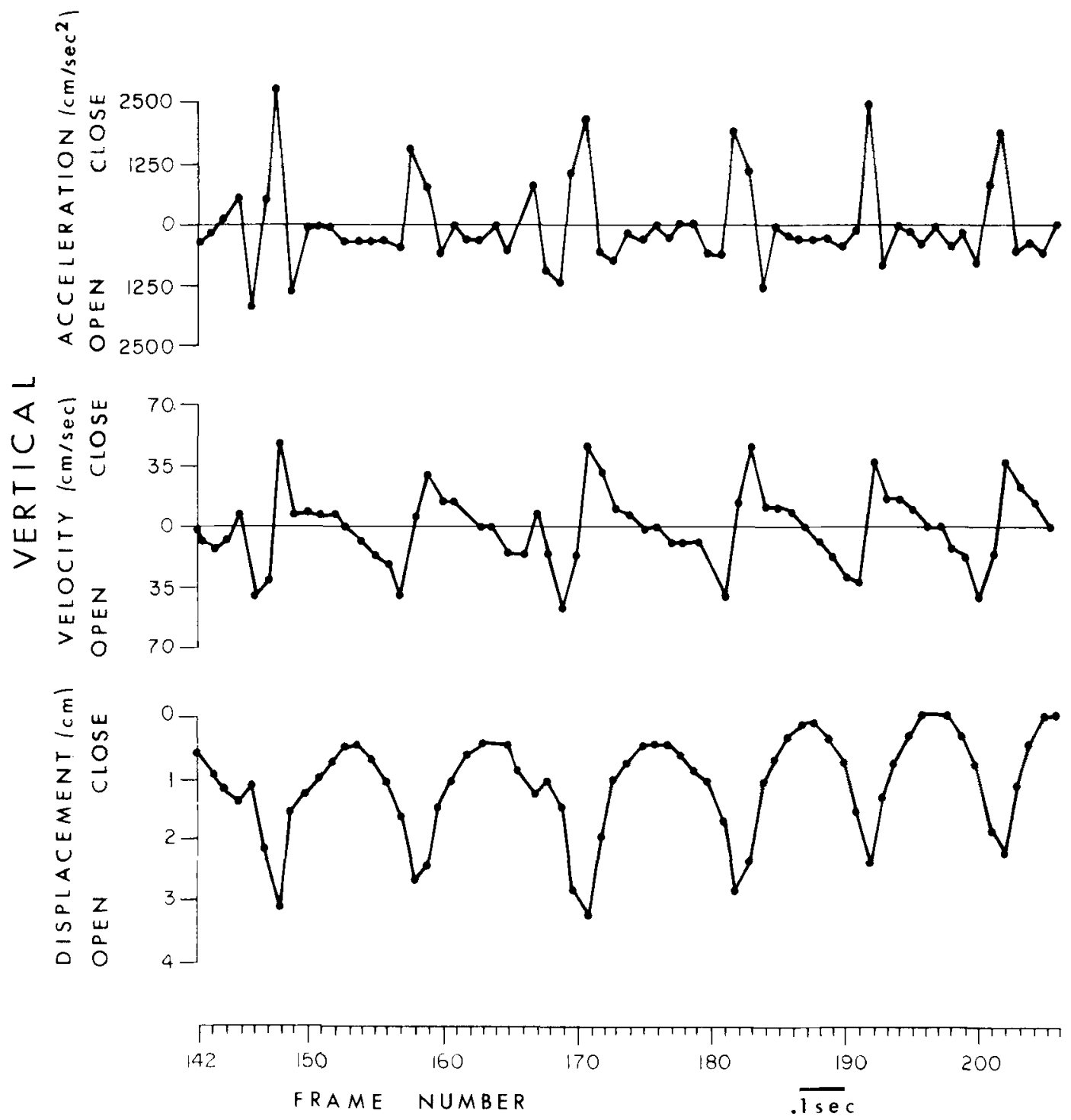

Fig. 7. F. catus. Vertical displacement (from films recorded at 35 frames per second), velocity, and acceleration of the base of the left lower canine (relative to the upper) in frontal view. Masticatory cycles when raw beef is being reduced in size near the middle of a reduction sequence.

objects laterally and posteriorly. However, small pieces of food are positioned mainly by dorsal and retrusive movements of the tongue. When manipulating such objects, the dorsally moving tongue may twist about its long axis so that its dorsal surface faces the working side.

In general, lateral transferrals of food require one or two masticatory cycles. Transfer occurs from a position with the mouth wide open into one with the mouth just starting to close. However, food is generally shifted backward along the carnassials during the closing phase. When the mandibular canines show either a slight reversing displacement or a hesitation during the opening phase, the tongue first protrudes between the canines, moves dorsally covering the upper incisors, and then retrudes into the oral cavity. We are uncertain about other movements of the tongue during this interval. 


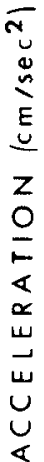

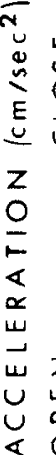

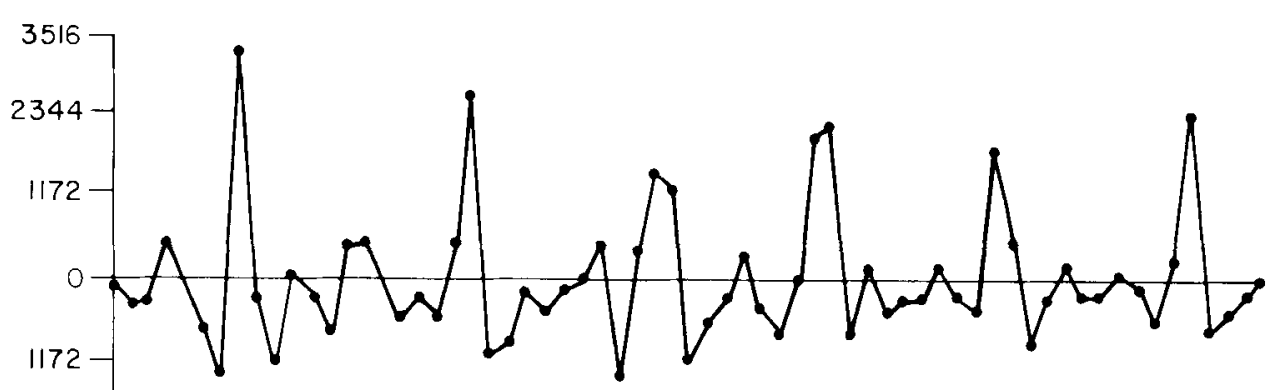

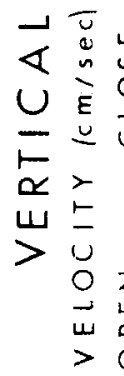
2344
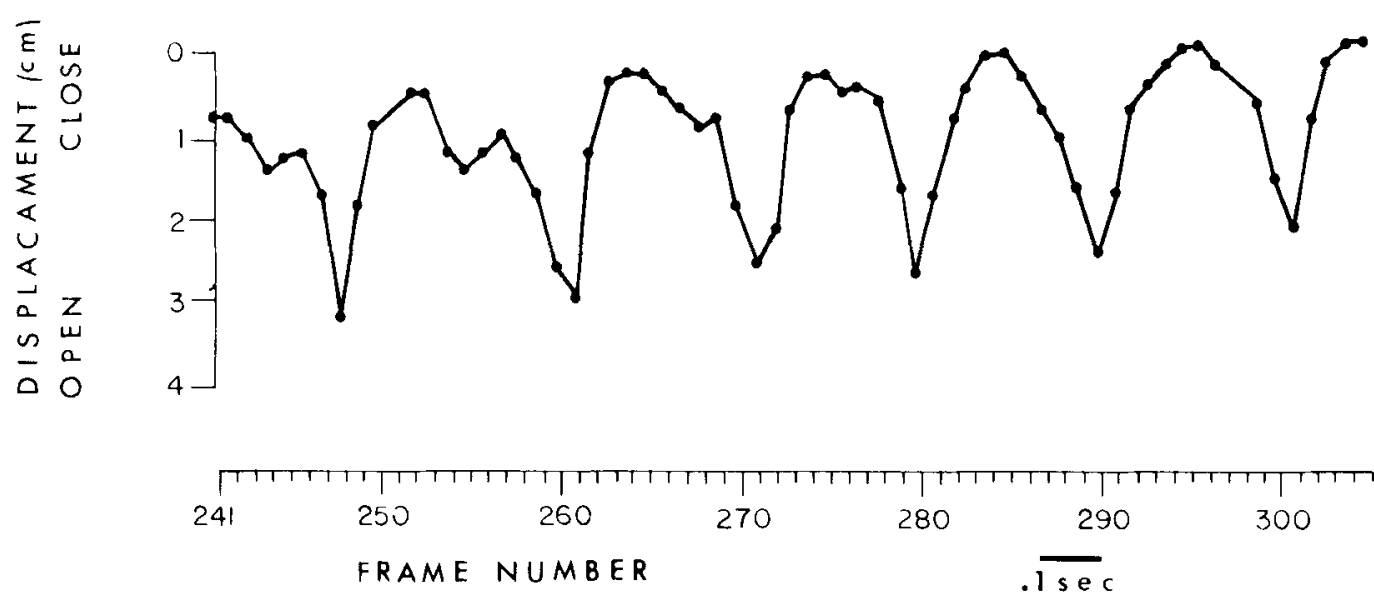

Fig. 8. F. catus. Vertical displacement (from films recorded at 34 frames per second), velocity and acceleration of the base of the left lower canine (relative to the upper) in frontal view. Masticatory cycles when cooked beef is being reduced near the middle of a reduction sequence. Note the irregular displacement during near-closure for cycles 1 through 4 , and the regular pattern for cycles 5 and 6 .

\section{ELECTROMYOGRAPHY}

\section{General pattern}

Electromyograms (EMGs) were obtained from the major jaw closing and opening muscles (Fig. 1) as well as from the biventer portion of the semispinalis capitis muscles. EMGs are described for masticatory cycles in which the working side was left. EMGs during ingestion are noted briefly thereafter.
In general, the periods of activity of the major masticatory muscles are bilaterally symmetrical; however, the periods of activity of the medial pterygoids and deep temporales are bilaterally asymmetrical (Fig. 12). Analysis of EMGs indicates that each muscle shows a relatively constant and characteristic pattern of activity correlated with fixed phases throughout most cycles of the reduction sequence. 

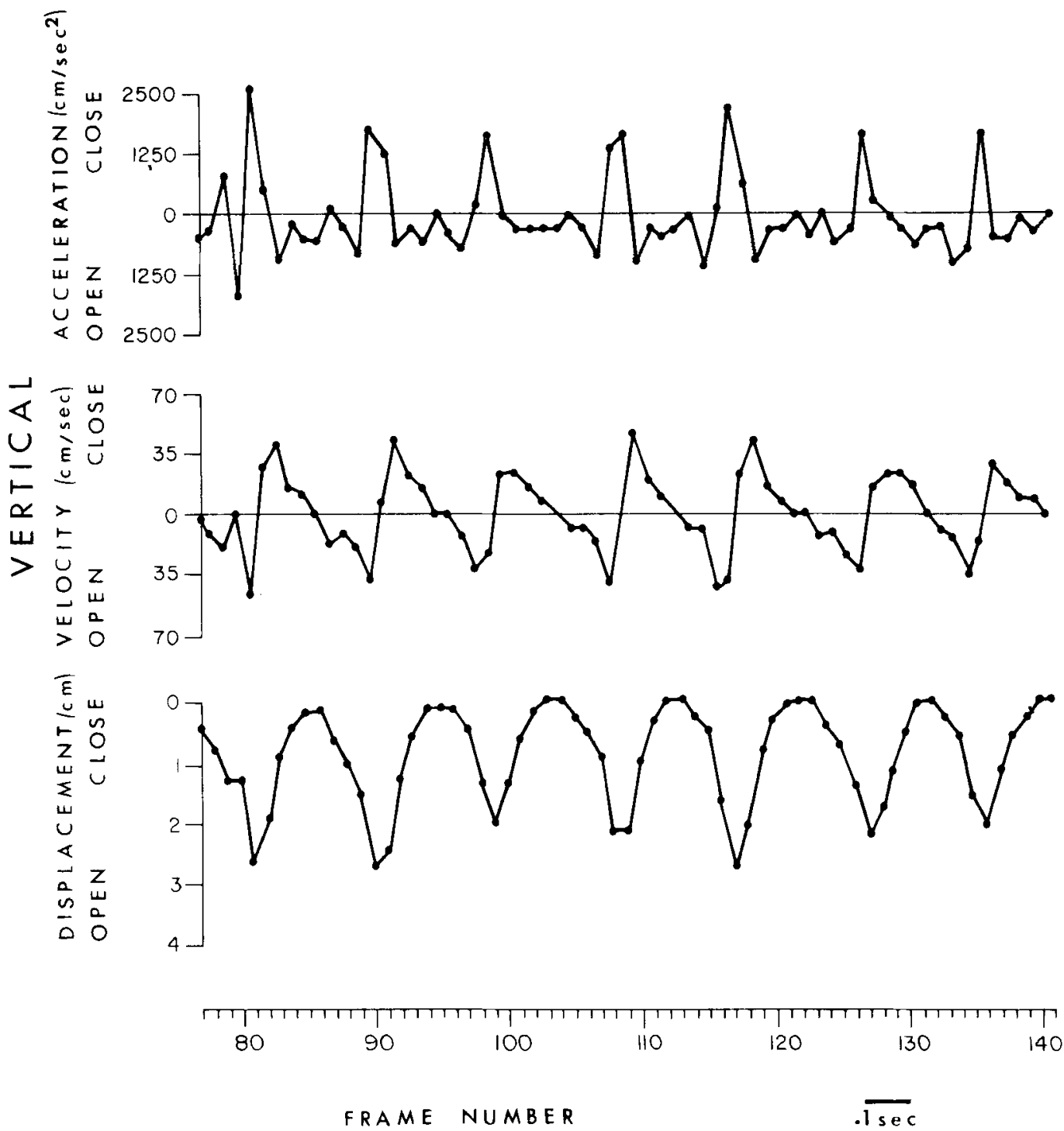

Fig. 9. F. catus. Vertical displacement (from films recorded at 35 frames per second), velocity, and acceleration of the base of the left lower canine (relative to the upper) in frontal view. Masticatory cycles when cooked chicken is being reduced near the middle of a reduction sequence. Note the regularly cyclic displacements.

In the following analysis of general activities during jaw opening, jaw closing, and movements of the head, we use verbal terms to characterize the level of activity during the sequences. In contrast, we characterize muscular activity in numerical terms in the section comparing the activities of adductors on the working and balancing sides and in that comparing the EMGs obtained when animals were reducing foods of different textures.
In a separate analysis, three standardized electrodes were placed in approximately equivalent sites within each side of the deep temporalis of four cats. The electrical activities were recorded at equivalent levels of amplification. The number and magnitude of EMG spikes during 30.5 msec intervals (defined by the filming rate) and the number of $30.5 \mathrm{msec}$ intervals per bite showing electrical results during closing were recorded. (Analysis is for 

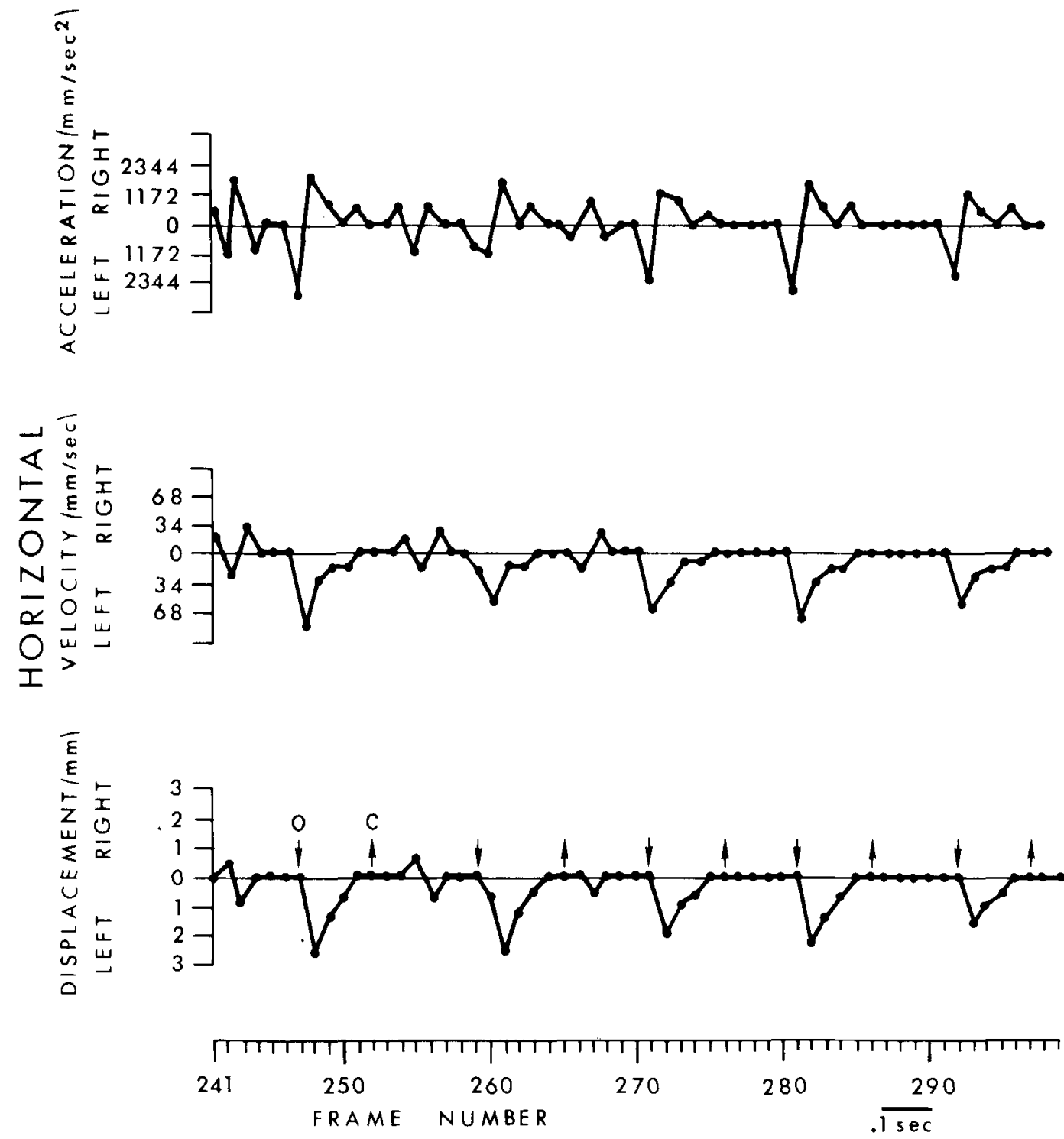

Fig. 10. F. catus. Horizontal displacement (from films recorded at 34 frames per second), velocity, and acceleration of the base of the left lower canine (relative to the upper) in frontal view. Masticatory cycles when cooked beef is being reduced near the middle of a reduction sequence. The arrows indicate instances when the jaws are wide-open $(\mathrm{O})$ and closed $(\mathrm{C})$. A horizontal displacement toward the working side (left) accompanies the closing phase. When raw and cooked beef are reduced, slight horizontal movements occur during opening, as shown for the first three cycles. Reduction of cooked chicken includes few horizontal displacements during opening; displacements then resemble those for cycles 4 and 5 of this figure.

only those intervals, during which the muscle was electrically active.) The mean values obtained on the test with both deep temporales did not differ significantly among electrodes on the same side or among cats, even at levels of significance greater than 0.2 (in one case the mean amplitude gave a test less than this but still above 0.05; Table 2). Furthermore, the mean numbers of spikes and the mean spike amplitudes, whether for the working or the balancing side, did not differ significantly ( $P>$ 0.10 ) if the working side was on the left or if it was on the right.

One can now establish confidence limits, both for the mean values expected within single bites and within smaller intervals. For the deep 

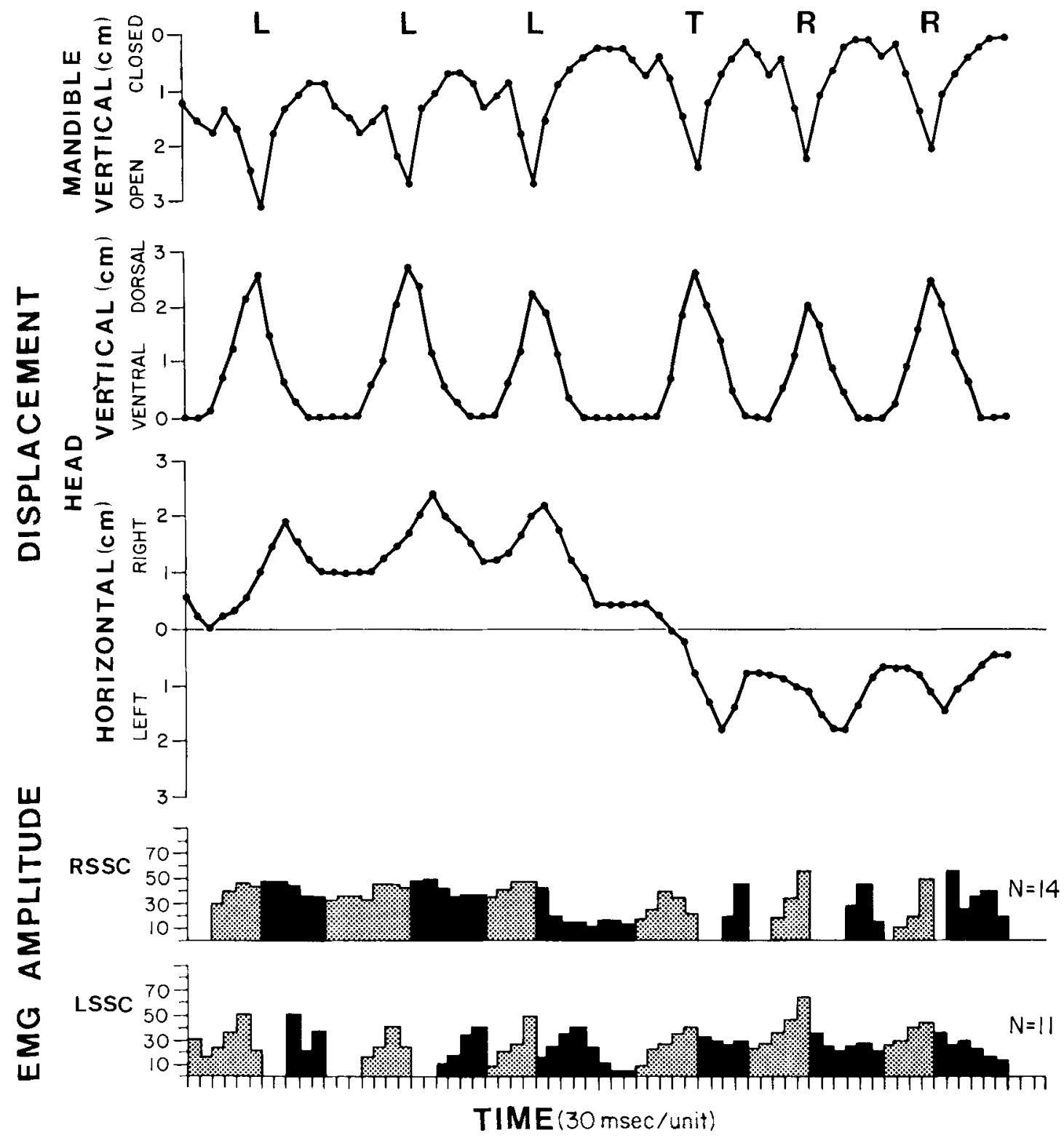

Fig. 11. F. catus. Summary of vertical displacement of the mandible, and vertical and horizontal displacements of the head (all from films recorded at 35 frames per second), as well as mean amplitudes ( $40 \mathrm{mV} / \mathrm{unit}$; taken from digitized electromyograms) of the right (RSSC) and left (LSSC) biventer portions of the semispinalis capitis muscles. Records show a representative series of masticatory cycles of a cat that is reducing cooked beef. ( $N$ equals the number of reduction sequences from which muscular activities were derived.) The bar graph is shown stippled for EMG activities during the opening phase and solid for activities during the closing phase. Note the changes in displacements of the head and of muscular activity coincident with opening and closing of the mandible, also the changes when the working side is transferred $(T)$ from the left $(L)$ to the right $(R)$. 
temporales, there is a $95 \%$ probability that the mean spike numbers (determined for a sequence of $30.5 \mathrm{msec}$ intervals) will fall within $6.38 \pm 0.36$ (mean $\pm 1 \mathrm{SE}$ ) for the working side muscle and $5.07 \pm 0.27$ for the balancing side one. The equivalent confidence limits for the spike amplitudes are $18.71 \pm 1.51$ for the working side muscle and $12.38 \pm 0.94$ for the balancing side one. When the comparison is based on the number and amplitude of the spikes per masticatory cycle (bites rather than intervals), the confidence limits for the number of spikes are $31.29 \pm 2.43$ for the working side and 22.37 \pm 1.97 for the balancing side one. Those for spike amplitudes are $93.82 \pm 11.14$ for the working side muscle and $50.92 \pm 5.19$ for the balancing side one. These results justify the comparisons of the output of multiple electrodes placed into different animals.

\section{Activity during opening}

The periods of activity of the anterior and posterior digastrics are bilaterally symmetrical during the opening phase of each cycle, as are the periods of activity of the anterior and posterior bellies of the same side (Fig. 13). Low levels of activity coincide with the start of opening, but stop during cycles that show slight closing movements during the opening phase. As jaw opening resumes, the digastrics become highly active bilaterally; their activity ceases when the mandible reaches the wide open position.

The zygomaticomandibulares and deep masseters fire bilaterally at low levels during slight closing displacements at the start of the opening phase (Fig. 14); they are silent thereafter. The zygomaticomandibulares again become slightly active when opening acceleration decreases near the end of the opening phase.

\section{Activity during closing}

As closing starts, the medial pterygoid of the balancing side and the deep temporalis of the working side become active at low levels, and the activity levels of the zygomaticomandibulares increase bilaterally (Fig. 14). This asymmetry in the start of activity of the medial pterygoid and the deep temporalis accompanies movement of the lower jaw toward the working side. As the mandible nears its farthest displacement toward the working side, the medial pterygoid of the working side starts to fire weakly, and the deep temporalis of the balancing side starts to fire strongly. Simultaneously, the deep and superficial masseters, as well as the superficial temporales of both sides, become slightly active. Also, the medial pterygoid of the balancing side and both zygomaticomandibulares show a rapid rise in activity.

Near midclosure, while the mandible is still displaced toward the working side, and while jaw closing acceleration decreases, all the jawclosing muscles are active bilaterally. The activity levels reach a maximum in the zygomaticomandibularis of the working side and the deep temporalis and medial pterygoid of the balancing side. Simultaneously, the zygomaticomandibularis, deep masseter, and superficial temporalis of the balancing side, as well as the deep masseter, deep and superficial temporales, and medial pterygoid of the working side, show increased levels of activity.

Near the end of closing, the deep and superficial masseters, and superficial temporales of both sides, as well as the medial pterygoid and deep temporalis of the working side, reach their maximal levels of activity. Zygomaticomandibulares of both sides and the medial pterygoid of the balancing side become less active at this time, although the zygomaticomandibulares are still active at relatively high levels.

The digastrics remain silent through the start of the closing phase and then start to fire. The anterior and posterior digastrics of the balancing side are more active than are those of the working side, as the mandibular canine on the working side moves horizontally toward the midline near the end of closing. Both anterior and posterior digastics of both sides cease activity as full closure is approached during a cycle. The digastics become less active as mandibular displacements decrease near the end of a reduction sequence.

Both lateral pterygoids appear to be silent during the opening phase and at the start of the closing phase of a cycle. Near the end of the closing phase, the lateral pterygoids become active simultaneously with the digastrics (Fig. 13). The lateral pterygoid of the working side is more active than that of the balancing side. The lateral pterygoids and digastrics simultaneously cease firing at the end of closing. Near the end of a reduction sequence, the lateral pterygoids are active at low levels at the end of closing.

When full closure is reached, the zygomaticomandibularis and the deep and superficial masseters of the balancing side, as well as the superficial masseter of the working side, stop firing. However, the other adductors may continue to show low levels of activity for varying periods of time. 


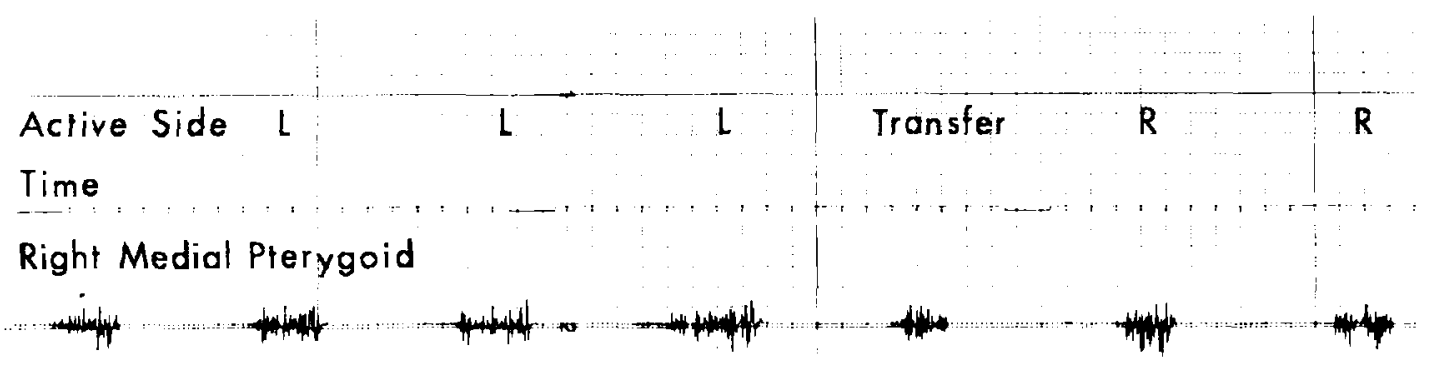

Left Medial Pterygoid

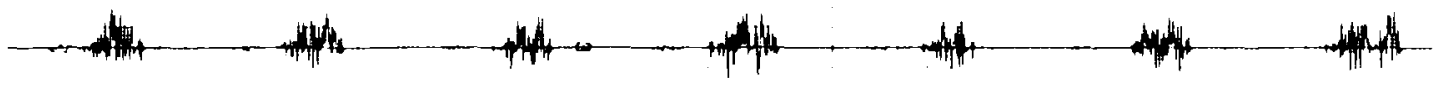

Right Deep Temporalis

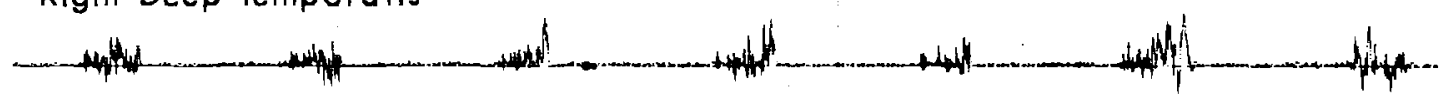

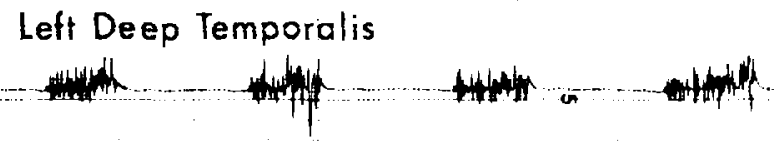

Frame Markers
80

90

100

110

120

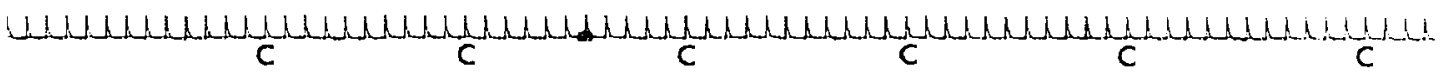

Fig. 12. F. catus. Representative electromyograms documenting asymmetric muscular activities of the medial pterygoid and deep temporalis muscles at the start of the closing phase (C). Initial horizontal movement toward the working side, whether left $(L)$ or right $(R)$, is accompanied by asymmetric activities of the deep temporales of the working side and the medial pterygoids of the balancing side. Digitized electromyograms were correlated with simultaneous movement records. 
TABLE 2. Activity of the temporales of the working and balancing side during reduction sequences of cooked beef by four different cats. *

\begin{tabular}{|c|c|c|c|c|c|c|c|c|}
\hline \multirow[b]{2}{*}{ Cat } & \multirow[b]{2}{*}{ Electrode } & \multirow[b]{2}{*}{$N$} & \multicolumn{2}{|c|}{$\begin{array}{c}\text { Mean number of } 30.5 \\
\text { msec intervals } \\
\text { showing activity }\end{array}$} & \multicolumn{2}{|c|}{$\begin{array}{c}\text { Mean number of spikes } \\
\text { per interval }\end{array}$} & \multicolumn{2}{|c|}{$\begin{array}{l}\text { Mean amplitude } \\
\text { per interval }\end{array}$} \\
\hline & & & $\begin{array}{l}\text { Working } \\
\text { mean } \pm \mathrm{SE}\end{array}$ & $\begin{array}{l}\text { Balancing } \\
\text { mean } \pm \mathrm{SE}\end{array}$ & $\begin{array}{l}\text { Working } \\
\text { mean } \pm \mathrm{SE}\end{array}$ & $\begin{array}{l}\text { Balancing } \\
\text { mean } \pm \mathrm{SE}\end{array}$ & $\begin{array}{l}\text { Working } \\
\text { mean } \pm \mathrm{SE}\end{array}$ & $\begin{array}{l}\text { Balancing } \\
\text { mean } \pm \mathrm{SE}\end{array}$ \\
\hline \multirow[t]{3}{*}{1} & A & 16 & $4.35 \pm 0.14$ & $3.87 \pm 0.15$ & $6.86 \pm 0.31$ & $5.20 \pm 0.35$ & $17.12 \pm 1.21$ & $11.78 \pm 0.79$ \\
\hline & B & 16 & $4.31 \pm 0.18$ & $4.06 \pm 0$ & $6.28 \pm 0.29$ & $4.94 \pm 0.26$ & $19.00 \pm 1.46$ & 11.01 \\
\hline & $\mathrm{C}$ & 16 & $4.62 \pm 0.23$ & & $6.21 \pm 0.21$ & & $20.59 \pm 1.19$ & \\
\hline \multirow[t]{3}{*}{2} & A & 16 & $4.37 \pm 0.13$ & $3.81 \pm 0.14$ & $6.80 \pm 0.38$ & $5.11 \pm 0.31$ & $19.48 \pm 1.32$ & $13.51 \pm 1.18$ \\
\hline & $\mathrm{B}$ & 16 & $4.12 \pm 0.18$ & $3.82 \pm 0$ & $6.27 \pm 0.33$ & \pm 0.36 & $19.15 \pm 2.23$ & $11.91 \pm 0.78$ \\
\hline & C & 16 & $4.42 \pm 0.24$ & $3.81 \pm 0.18$ & $6.07 \pm 0.31$ & $5.19 \pm 0.29$ & $17.59 \pm 1.84$ & $11.61 \pm 0.9$ \\
\hline \multirow[t]{3}{*}{3} & A & 16 & $4.62 \pm 0.22$ & $3.69 \pm 0.19$ & $6.29 \pm 0.35$ & $4.79 \pm 0.28$ & $19.86 \pm 0.99$ & $10.94 \pm 0.82$ \\
\hline & B & 16 & $4.75 \pm 0.21$ & $3.76 \pm 0.19$ & $6.27 \pm 0.27$ & $4.61 \pm 0.27$ & $18.59 \pm 1.06$ & $12.33 \pm 1.12$ \\
\hline & $\mathrm{C}$ & 16 & $4.56 \pm 0.22$ & $3.74 \pm 0.19$ & $6.05 \pm 0.28$ & $4.84 \pm 0.29$ & $19.53 \pm 1.45$ & $12.26 \pm 0.91$ \\
\hline \multirow[t]{3}{*}{4} & A & 16 & & $3.69 \pm 0.18$ & & $5.17 \pm 0.40$ & & $11.23 \pm 1.2$ \\
\hline & $\mathrm{B}$ & 16 & $4.50 \pm 0.2$ & $3.81 \pm 0.19$ & $6.41 \pm 0.43$ & $4.78 \pm 0.32$ & $17.51 \pm 1.48$ & $11.57 \pm 1.1$ \\
\hline & $\mathrm{C}$ & 16 & $4.56 \pm 0.18$ & $3.62 \pm 0.22$ & $6.15 \pm 0.35$ & $4.92 \pm 0.42$ & $19.11 \pm 1.52$ & $11.34 \pm 0.91$ \\
\hline
\end{tabular}

*Records from six electrodes per cat placed into closely proximate sites in the deep temporalis of each side. Mean numbers of 30.5 msec intervals showing activity during a bite, mean numbers of EMG spikes, and mean spike amplitudes (in terms of 40 mV/unit) each per interval for different electrodes. ( $N$ equals the number of bites.)

\section{Activity during movements of the head}

The biventer portions of the semispinalis capitis muscles are active as the head moves upward and sidewards (Fig. 11). When the head is held facing toward the balancing side, the semispinalis capitis of the balancing side remains active throughout both the opening and closing phases of a masticatory cycle. Activity of the muscle of the balancing side increases when the head moves upward and toward the balancing side during opening and at the start of closing. Activity decreases slightly as the head shifts toward the working side during the last half of the closing phase.

The semispinalis capitis of the working side starts to fire at a low level as the head begins to move upward during opening. The muscle becomes more active as the head jerks upward and opening acceleration of the mandible decreases. Its activity ceases as the head jerks downward at the start of the closing phase. However, movement of the head toward the working side during the last half of closing is coincident with marked activity of the semispinalis capitis on the working side; activity then stops as the head becomes still.

If food is transferred between sides during a reduction sequence, the semispinalis capitis on the balancing side becomes much less active as the head moves farther toward the working side. At the same time, the muscle of the working side is slightly active. This activity then increases as the head shifts farther toward the working (new balancing) side and as the head is lifted during the opening phase of the following cycle.

\section{Activities during ingestion}

The anterior and posterior digastrics are active bilaterally and symmetrically during opening. Low levels of activity coincide with slight opening of the mouth as the tongue protrudes. The digastrics then become highly active as the mouth opens rapidly, but activity ceases bilaterally when the mouth reaches the wide-open position. During ingestion, the digastrics and the lateral pterygoids appear to be silent while the mouth is closing.

The adductors of both sides are active in bilateral symmetry while the mouth closes. In general, these adductors are more active and for a longer period during ingestion than during chewing. Although the times of activity are the same, the adductors of the working side are more active than those of the balancing side. The adductors become silent when the mouth starts to open.

Activity of the biventer portions of the semispinalis capitis during upward and lateral movements of the head agrees with that observed during mastication. Both sides of this muscle are highly active as the head moves upward during opening and less active as the head moves downward during closing. As the head moves laterally, activity occurs on the side toward which movement proceeds.

\section{Comparisons of adductor activities}

Tables 3-5 show EMG activities recorded on the same day from a single set of electrodes implanted unilaterally within the designated muscles of a single cat. The values are for two entire reduction sequences during which either 

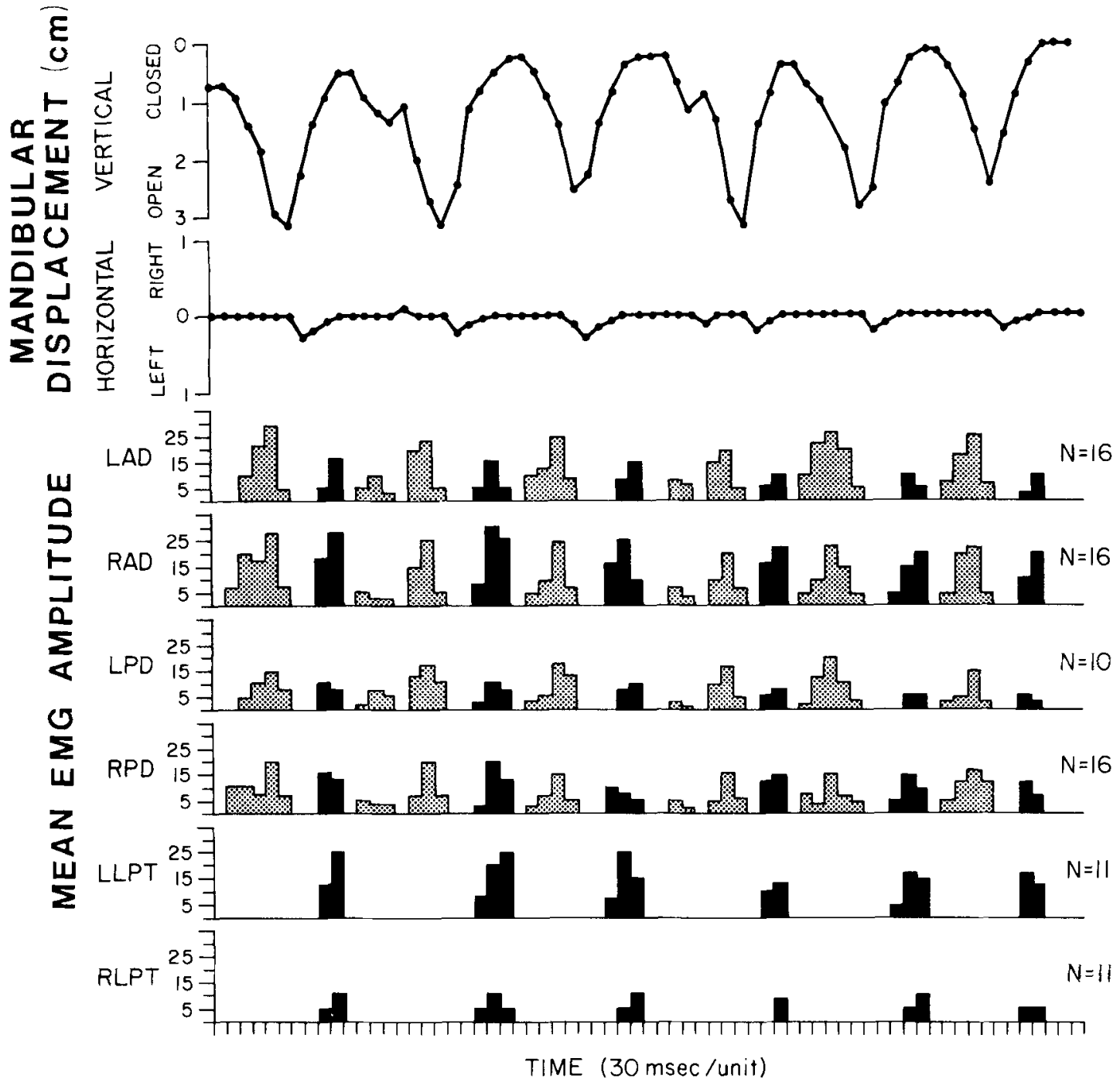

Fig. 13. F. catus. Synthetic summary of sequences of mandibular displacements and coincident mean amplitudes (40 $\mathrm{mV}$ /unit) of (digitized) electromyograms of the anterior (AD) and posterior (PD) digastrics and lateral pterygoids (LPT) muscles. The prefix $L$ denotes left; $R$, right. The bar graph is shown stippled when the EMGs occur during the opening phase and solid when they occur during the closing phase. The left side is working throughout the sequence. $N$ equals the number of reduction sequences used to obtain mean muscular activities. See text for explanation.

Fig. 14. F. catus. Synthetic summary of sequences of mandibular displacements and coincident mean amplitudes (40 $\mathrm{mV}$ /unit) of (digitized) EMGs of the zygomaticomandibularis (ZM); deep masseter (DM); superficial masseter (SM); deep temporalis (DT); superficial temporalis (ST); and medial pterygoid (MPT) muscles. The prefix L denotes left; R, right. The bar graph is shown stippled when the EMGs occur during the opening phase and solid when they occur during the closing phase. The left side is working throughout the sequence. $N$ equals the number of reduction sequences used to obtain mean muscular activities. See text for explanation. 


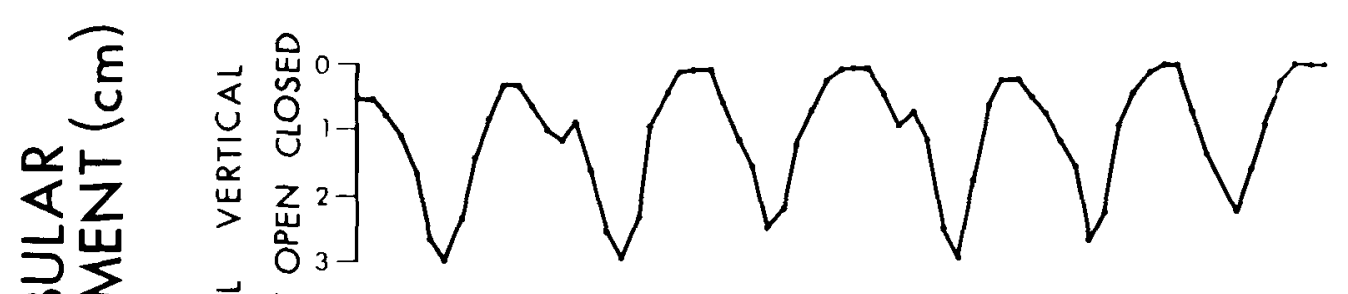

$\sum \frac{1}{2} \frac{\pi}{0}$

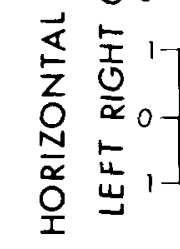

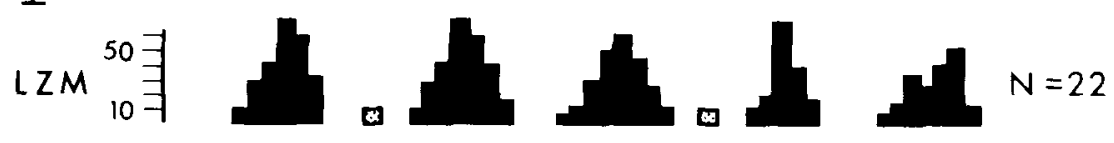
LDM ${ }_{10}^{50}$ RDM ${ }_{10}^{50}$ 年 $\mathrm{N}=38$

㟔 LSM ${ }^{50}{ }^{50}$ 年

三 $R S{ }_{10}^{50}{ }_{10}^{50}, N=30$

$\sum_{<}^{2}{ }_{\text {LOT }}{ }_{10}^{50}{ }_{10}^{10}$

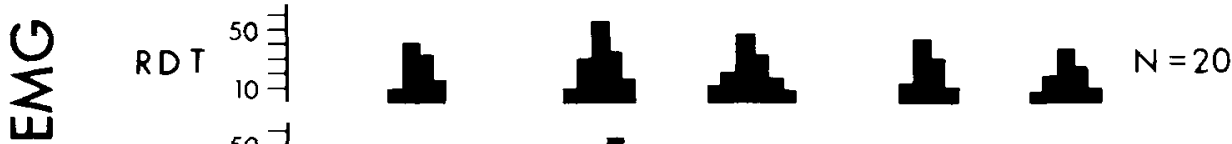

$Z$ LST ${ }_{10}^{50}$ 每

$\sum^{4}$ RST ${ }_{10}^{50}$ 岁

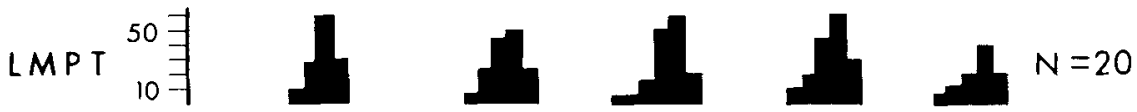

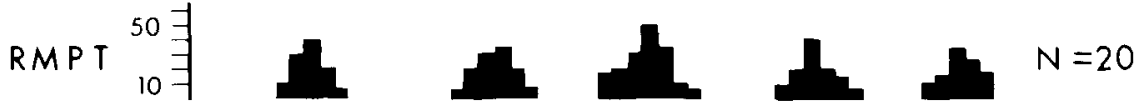


TABLE 3. Muscular activity during mastication of cooked beef by a single cat. $\dagger$

\begin{tabular}{|c|c|c|c|c|c|c|c|}
\hline \multirow[b]{2}{*}{ Muscles } & \multirow[b]{2}{*}{$\mathbf{N}$} & \multicolumn{2}{|c|}{$\begin{array}{c}\text { Mean number of } 30.5 \\
\text { msec intervals } \\
\text { showing activity }\end{array}$} & \multicolumn{2}{|c|}{$\begin{array}{c}\text { Mean number of spikes } \\
\text { per interval }\end{array}$} & \multicolumn{2}{|c|}{$\begin{array}{l}\text { Mean amplitude } \\
\text { per interval }\end{array}$} \\
\hline & & $\begin{array}{l}\text { Working } \\
\text { mean } \pm \mathrm{S} E\end{array}$ & $\begin{array}{l}\text { Balancing } \\
\text { mean } \pm \mathrm{SE}\end{array}$ & $\begin{array}{c}\text { Working } \\
\text { mean } \pm \mathrm{SE}\end{array}$ & $\begin{array}{c}\text { Balancing } \\
\text { mean } \pm \mathrm{SE}\end{array}$ & $\begin{array}{l}\text { Working } \\
\text { mean } \pm \mathrm{SE}\end{array}$ & $\begin{array}{l}\text { Balancing } \\
\text { mean } \pm \mathrm{SE}\end{array}$ \\
\hline ST & 25 & $3.37 \pm 0.16$ & $3.24 \pm 0.18$ & $5.18 \pm 0.35$ & $3.94 \pm 0.24^{*}$ & $15.07 \pm 1.16$ & $10.84 \pm 1.08^{*}$ \\
\hline DT & 25 & $4.08 \pm 0.16$ & $3.28 \pm 0.17^{*}$ & $6.36 \pm 0.34$ & $5.16 \pm 0.34^{*}$ & $17.96 \pm 1.15$ & $12.62 \pm 0.84^{*}$ \\
\hline $\mathrm{ZM}$ & 25 & $4.17 \pm 0.18$ & $4.12 \pm 0.18$ & $7.12 \pm 0.32$ & $6.71 \pm 0.35$ & $22.14 \pm 1.74$ & $16.94 \pm 1.28^{*}$ \\
\hline $\mathrm{DM}$ & 25 & $3.59 \pm 0.11$ & $3.53 \pm 0.10$ & $10.14 \pm 0.42$ & $8.21 \pm 0.35^{*}$ & $26.67 \pm 1.91$ & $14.83 \pm 0.83^{*}$ \\
\hline SM & 25 & $3.13 \pm 0.15$ & $3.12 \pm 0.11$ & $6.26 \pm 0.33$ & $4.80 \pm 0.27^{*}$ & $7.59 \pm 0.68$ & $5.64 \pm 0.58 *$ \\
\hline MPT & 25 & $3.69 \pm 0.16$ & $4.05 \pm 0.11$ & $8.29 \pm 0.49$ & $7.73 \pm 0.50$ & $23.82 \pm 1.90$ & $17.53 \pm 1.59^{*}$ \\
\hline
\end{tabular}

† Mean numbers of $\mathbf{3 0 . 5}$ msec intervals showing EMG activity per bite, mean numbers of EMG spikes per interval, and mean spike amplitudes (in terms of $40 \mathrm{mV} /$ unit) per interval for adductors on the working and balancing sides during two reduction sequences. ( $N$ equals the number of bites. Muscle abbreviations as in Figure 14.)

* Significantly different from the same muscle on the working side at $P<0.01$.

TABLE 4 Muscular activity during mastication of cooked beef by a single cat.*

\begin{tabular}{ccccc}
\hline & & Start & Middle & End \\
Muscles & $\mathrm{N}$ & $\begin{array}{c}\text { Mean number } \\
\text { of intervals } \\
\text { mean } \pm \mathrm{SE}\end{array}$ & $\begin{array}{c}\text { Mean number } \\
\text { of intervals } \\
\text { mean } \pm \mathrm{SE}\end{array}$ & $\begin{array}{c}\text { Mean number } \\
\text { of intervals } \\
\text { mean } \pm \mathrm{SE}\end{array}$ \\
\hline WST & 10 & $3.90 \pm 0.23$ & $3.60 \pm 0.16$ & $3.09 \pm 0.28$ \\
BST & 10 & $3.70 \pm 0.21$ & $3.45 \pm 0.16$ & $3.10 \pm 0.24$ \\
WDT & 10 & $4.36 \pm 0.15$ & $3.80 \pm 0.29$ & $3.72 \pm 0.24$ \\
BDT & 10 & $3.80 \pm 0.20$ & $3.50 \pm 0.22$ & $3.20 \pm 0.29$ \\
& & & & \\
WZM & 10 & $4.40 \pm 0.31$ & $4.10 \pm 0.28$ & $3.80 \pm 0.25$ \\
BZM & 10 & $4.36 \pm 0.21$ & $4.09 \pm 0.16$ & $3.80 \pm 0.20$ \\
WDM & 10 & $3.80 \pm 0.25$ & $3.60 \pm 0.22$ & $3.40 \pm 0.16$ \\
BDM & 10 & $3.72 \pm 0.19$ & $3.50 \pm 0.17$ & $3.20 \pm 0.13$ \\
& & & & \\
WSM & 10 & $3.50 \pm 0.22$ & $3.40 \pm 0.22$ & $2.80 \pm 0.13$ \\
BSM & 10 & $3.30 \pm 0.21$ & $3.18 \pm 0.12$ & $2.90 \pm 0.25$ \\
WMPT & 10 & $3.70 \pm 0.26$ & $3.60 \pm 0.22$ & $3.39 \pm 0.16$ \\
BMPT & 10 & $4.30 \pm 0.26$ & $3.90 \pm 0.23$ & $3.72 \pm 0.16$ \\
\hline
\end{tabular}

* Mean numbers of 30.5 msec intervals showing activity per bite for adductors on the working (W) and balancing (B) sides during the start, middle, and end of a reduction sequence. ( $N$ equals the number of bites. Muscle abbreviations as in Figure 14.)

the working or balancing side remains relatively constant. They agree well with recordings of the same muscles in other cats.

EMGs for an adductor on the working or balancing side for an entire reduction sequences may now be compared. Comparison is of 1) the duration of the activity period for each bite-i.e., the mean numbers of $30.5 \mathrm{msec}$ (set by filming rate) intervals per bite during which the muscle is electrically active during the closing phase, of 2) the mean number of spikes, as well as of 3 ) the mean spike amplitudes per interval (Table 4). The deep temporalis is unique in that the mean activity period per bite is significantly greater when the muscle is on the working side than on the balancing one; in all other muscles this is not significantly different. However, the mean activity periods are greatest for the zygomaticomandibularis either on the working or on the balancing side. The relative durations of activity periods of each muscle per bite reflect the changing times of onset and cessation of adductor activity described above. 
TABLE 5. Muscular activities at the start, middle and end of a reduction sequence of cooked beef by a single cat. $\dagger$

\begin{tabular}{|c|c|c|c|c|c|c|c|}
\hline \multirow[b]{2}{*}{ Muscles } & \multirow[b]{2}{*}{$\mathbf{N}$} & \multicolumn{2}{|c|}{ Start } & \multicolumn{2}{|c|}{ Middle } & \multicolumn{2}{|c|}{ End } \\
\hline & & $\begin{array}{c}\text { Mean numbers } \\
\text { of spikes } \\
\text { mean } \pm S E\end{array}$ & $\begin{array}{l}\text { Mean EMG } \\
\text { amplitudes } \\
\text { mean } \pm \mathrm{SE}\end{array}$ & $\begin{array}{c}\text { Mean numbers } \\
\text { of spikes } \\
\text { mean } \pm \mathrm{SE}\end{array}$ & $\begin{array}{c}\text { Mean EMG } \\
\text { amplitudes } \\
\text { mean } \pm \mathrm{SE}\end{array}$ & $\begin{array}{c}\text { Mean numbers } \\
\text { of spikes } \\
\text { mean } \pm \mathrm{SE}\end{array}$ & $\begin{array}{c}\text { Mean EMG } \\
\text { amplitudes } \\
\text { mean } \pm \mathrm{SE}\end{array}$ \\
\hline WST & 10 & $5.92 \pm 0.56$ & $17.48 \pm 2.30$ & $5.30 \pm 0.60$ & $15.02 \pm 1.63$ & $4.90 \pm 0.51$ & $13.80 \pm 1.80$ \\
\hline BST & 10 & $4.35 \pm 0.45$ & $12.05 \pm 1.28$ & $3.80 \pm 0.36$ & $10.54 \pm 1.19$ & $3.65 \pm 0.39$ & $6.88 \pm 0.74 !^{*}$ \\
\hline WDT & 10 & $7.48 \pm 0.51$ & $18.80 \pm 2.07$ & $6.16 \pm 0.46$ & $16.80 \pm 1.80$ & $5.39 \pm 0.52 !$ & $15.34 \pm 2.00$ \\
\hline $\mathrm{BDT}$ & 10 & $5.34 \pm 0.41^{*}$ & $16.00 \pm 1.43$ & $5.11 \pm 0.38$ & $13.57 \pm 1.36$ & $4.58 \pm 0.48$ & $12.11 \pm 1.04$ \\
\hline WZM & 10 & $8.23 \pm 0.36$ & $25.38 \pm 2.90$ & $6.62 \pm 0.47$ & $20.62 \pm 2.40$ & $5.97 \pm 0.48 !$ & $20.35 \pm 2.50$ \\
\hline BZM & 10 & $7.36 \pm 0.52$ & $21.61 \pm 2.90$ & $6.87 \pm 0.52$ & $14.46 \pm 3.10$ & $5.75 \pm 0.52$ & $11.05 \pm 2.00 \%$ \\
\hline WDM & 10 & $11.08 \pm 0.73$ & $34.85 \pm 3.06$ & $9.23 \pm 0.63$ & $30.05 \pm 2.86$ & $8.10 \pm 0.65 !$ & $24.31 \pm 2.39$ \\
\hline BDM & 10 & $8.86 \pm 0.59$ & $22.14 \pm 1.67^{*}$ & $7.90 \pm 0.63$ & $15.11+1.48 !^{*}$ & $7.79 \pm 0.55$ & $12.60 \pm 0.94 !^{*}$ \\
\hline WSM & 10 & $6.87 \pm 0.51$ & $12.04 \pm 1.51$ & $5.46 \pm 0.46$ & $6.45 \pm 0.66 !$ & $5.19 \pm 0.61$ & $5.11 \pm 0.56 !$ \\
\hline BSM & 10 & $5.30 \pm 0.43$ & $5.62 \pm 0.59^{*}$ & $4.58 \pm 0.39$ & $4.97 \pm 0.42 !$ & $4.21 \pm 0.32$ & $3.22 \pm 0.28 !^{*}$ \\
\hline WMPT & 10 & $9.81 \pm 0.65$ & $31.58 \pm 3.65$ & $7.79 \pm 0.55$ & $24.19 \pm 2.75$ & $7.36 \pm 0.69$ & $15.75 \pm 2.04 !$ \\
\hline BMPT & 10 & $7.78 \pm 0.63$ & $21.46 \pm 2.78$ & $7.61 \pm 0.65$ & $20.25 \pm 1.70$ & $7.75 \pm 0.71$ & $14.66 \pm 1.53$ \\
\hline
\end{tabular}

†Mean number of EMG spikes and mean EMG spike amplitudes (in terms of $40 \mathrm{mV} /$ unit) during the same intervals as those in Table 4 for adductors on the working (W) and balancing (B) side. (N equals the number of bites. Muscle abbreviations as in Figure 14.)

*Significantly different from the same muscle on the working side at $P<0.01$.

!Significantly different from the start at $P<0.01$.

The deep and superficial temporales, as well as the deep and superficial masseters, show significantly greater mean numbers of spikes and mean amplitudes on the working than on the balancing side. However, the zygomaticomandibularis and the medial pterygoid only show significantly greater mean amplitudes (but not spike numbers) on the working than on the balancing side.

When these descriptors are used to characterize muscular activities observed during the beginning, middle, and end of reduction sequences, they disclose further similarities and differences. In general, the duration of bite, number of spikes, and mean spike amplitudes decrease during a reduction sequence. However, only some of the regular decreases result in statistically significant differences (Tables 4 and 5). In none of the adductors studied is the mean activity period per bite significantly different when an adductor is on the working or on the balancing side, nor do the activity periods differ significantly for either muscle of a pair between the beginning and the end of a reduction sequence.

Only for the deep temporalis is the mean number of spikes significantly greater when the muscle is on the working than on the balancing side (and then only at the beginning of a sequence). For no other adductor do the mean numbers of spikes differ significantly between working and balancing sides during the middle or the end of a reduction sequence; however, the values are generally greater throughout a sequence when the muscle is on the working side than on the balancing side.

For the deep temporalis, zygomaticomandibularis, and deep masseter, all of the working side, the mean numbers of spikes are significantly greater at the beginning than at the end of a sequence. However, in no adductor do the mean numbers of spikes differ significantly between the beginning and the middle, or between the middle and the end, of a reduction sequence. Still, all adductors show the greatest mean numbers of spikes at the beginning of a sequence and a drop thereafter.

The superficial and deep temporales show greater mean amplitudes throughout a reduction sequence when the muscle is on the working side than when it is on the balancing side (Table 5). The mean amplitudes are greatest at the beginning of a reduction sequence, and drop thereafter. However, the superficial temporalis shows a significantly greater mean amplitude for the working than for the balancing side at the end of a reduction sequence; the amplitude of the events on the balancing side also decreases significantly between the beginning and the end of a sequence. 
The mean amplitudes of the zygomaticomandibularis and of the deep and superficial masseters are greater on the working than on the balancing side. However, it is only near the end of a reduction sequence that the amplitudes for the zygomaticomandibularis become significantly greater on the working than on the balancing side. In contrast, amplitudes between the working and balancing side of the deep masseter are significantly different throughout a sequence, whereas amplitudes of the superficial masseter are significantly greater at the start and end of a sequence. Amplitudes for the deep masseter on the balancing side and for the superficial masseter on both sides are significantly greater at the beginning than during the middle or at the end of a reduction sequence. However, the differences between the start and the end of a sequence are not significant for the zygomaticomandibularis and deep masseter on the working side, but the differences between the beginning and the end of a sequence are significant for the zygomaticomandibularis on the balancing side. The various comparisons of the activity of the medial pterygoids only show significant differences between the output of the working side at the beginning and the end of a sequence.

In general, in adductors, whether on the working or the balancing side, the mean number of spikes per interval tends to be correlated positively with the mean spike amplitude $(\mathrm{r}=0.79$ at $\mathrm{P}<0.01$; Tables 3-5). However, a pairwise comparison of the numbers of spikes with the spike amplitudes for each sampled interval does not yield a significant correlation. Mean numbers of spikes and mean spike amplitude also correlate positively when the activities of all adductors throughout an entire reduction sequence are compared simultaneously ( $r=0.84$ at $\mathrm{P}<0.01$; Tables $3-5$ ).

\section{Variation of EMG with food type}

When a single set of electrodes is implanted within the adductors on the working side of a single cat, the mean activity periods per bite (Table 6) and the mean number of spikes as well as mean spike amplitudes (Table 7) differ when cats masticate raw beef, cooked beef, and cooked chicken. In general, these means are greatest for raw beef, less for cooked beef, and least for chicken.

For all adductors, the mean activity periods are significantly greater when cats chew raw beef than when they chew chicken. Only the zygomaticomandibularis, superficial masseter, and the medial pterygoid show significantly greater mean activity periods for raw than for cooked beef. None of the adductors show significantly different periods of activity when cats chew either cooked beef or chicken.

The superficial and deep temporales, and the superficial masseter show significantly greater mean numbers of spikes when cats chew raw beef than when they masticate either cooked beef or chicken. However, the mean number of spikes for the zygomaticomandibularis does not differ significantly between raw and cooked beef, but the mean number of spikes is significantly greater for raw beef than for cooked chicken. The mean number of spikes for the deep masseter also does not differ significantly between raw and cooked beef, but the mean number of spikes is significantly greater for raw and cooked beef than for chicken. The mean number of spikes for the medial pterygoid does not differ significantly when cats chew either raw or cooked beef or chicken.

For all adductors, the mean spike amplitudes are significantly greater when cats chew raw and cooked beef than when they chew chicken. The mean amplitudes of the superficial and deep temporales, the superficial masseter, and the medial pterygoid also are significantly greater for raw beef rather than cooked beef. However, the mean amplitudes of the zygomaticomandibularis and deep masseter are insignificantly different for raw than for cooked beef, although they are greater for raw beef.

For the temporales, superficial masseter, and the medial pterygoid of the working side, the mean number of intervals per bite (temporales and medial pterygoid only), the mean numbers of spikes, mean spike amplitudes, and the products of these means (i.e., the mean number of spikes times the mean amplitude) show a faint but significant $(\mathrm{P}<0.05)$ positive correlation with the mean penetrometer values for the different food types offered (Table 8). Although the same descriptors of EMG activity for the zygomaticomandibularis and deep masseter of the working side also appear to indicate a positive correlation with food type, the correlation coefficients are insignificant.

\section{DISCUSSION}

\section{Movements}

Food is reduced in the mouth between the moving dental arcades. Consequently, studies of mastication emphasize movements of the mandible and the muscular activities generating them. However, movements of the whole 
TABLE 6. Muscular activity during mastication of three distinct food types by a single cat. $\dagger$

\begin{tabular}{|c|c|c|c|c|c|c|c|c|c|}
\hline \multirow[b]{2}{*}{ Muscles } & \multicolumn{2}{|c|}{ Raw beef } & \multicolumn{3}{|c|}{ Cooked beef } & \multicolumn{3}{|c|}{ Cooked chicken } & \multirow[b]{2}{*}{$\mathrm{N}$} \\
\hline & $\begin{array}{c}\text { Mean } \\
\text { number of } \\
\text { intervals } \\
\text { mean } \pm \mathrm{SE}\end{array}$ & $\begin{array}{c}\text { Mean } \\
\text { number of } \\
\text { spikes } \\
\text { mean } \pm \mathrm{SE}\end{array}$ & $\mathrm{N}$ & $\begin{array}{c}\text { Mean } \\
\text { number of } \\
\text { intervals } \\
\text { mean } \pm \mathrm{SE}\end{array}$ & $\begin{array}{c}\text { Mean } \\
\text { number of } \\
\text { spikes } \\
\text { mean } \pm \mathrm{SE}\end{array}$ & $\mathrm{N}$ & $\begin{array}{c}\text { Mean } \\
\text { number of } \\
\text { intervals } \\
\text { mean } \pm \mathrm{SE}\end{array}$ & $\begin{array}{c}\text { Mean } \\
\text { number of } \\
\text { spikes } \\
\text { mean } \pm \mathrm{SE}\end{array}$ & \\
\hline ST & $3.85 \pm 0.10$ & $7.79 \pm 0.20$ & 63 & $3.37 \pm 0.16$ & $5.18 \pm 0.35^{*}$ & 25 & $3.23 \pm 0.12^{*}$ & $4.72 \pm 0.35^{*}$ & 20 \\
\hline DT & $4.52 \pm 0.12$ & $8.48 \pm 0.23$ & 63 & $4.08 \pm 0.16$ & $6.36 \pm 0.34^{*}$ & 25 & $3.66 \pm 0.14^{*}$ & $5.17 \pm 0.34^{*}$ & 20 \\
\hline $\mathrm{ZM}$ & $5.01 \pm 0.12$ & $7.66 \pm 0.23$ & 63 & $4.17 \pm 0.18^{*}$ & $7.12 \pm 0.34$ & 25 & $4.45 \pm 0.11^{*}$ & $6.31 \pm 0.38^{*}$ & 20 \\
\hline DM & $3.79 \pm 0.10$ & $10.49 \pm 0.28$ & 63 & $3.59 \pm 0.12$ & $10.14 \pm 0.42$ & 25 & $3.30 \pm 0.13^{*}$ & $7.79 \pm 0.54^{* *}$ & 20 \\
\hline SM & $3.66 \pm 0.08$ & $8.80 \pm 0.26$ & 63 & $3.13 \pm 0.11^{*}$ & $6.26 \pm 0.32^{*}$ & 25 & $3.20 \pm 0.12^{*}$ & $4.50 \pm 0.27^{*}$ & 20 \\
\hline MPT & $3.93 \pm 0.15$ & $8.59 \pm 0.42$ & 63 & $3.30 \pm 0.16^{*}$ & $8.29 \pm 0.49$ & 25 & $3.29 \pm 0.11^{*}$ & $8.24 \pm 0.45$ & 20 \\
\hline
\end{tabular}

†Mean numbers of $30.5 \mathrm{msec}$ intervals showing EMG activity per bite and mean numbers of EMG spikes per interval for the working side adductors during two reduction sequences. (N equals the number of bites. Muscle abbreviations as in Figure 14.)

* Significantly different from raw beef at $P<0.01$.

**Significantly different from raw and cooked beef at $\mathrm{P}<0.01$

TABLE 7. Muscular activity during mastication of three distinct food types by a single cat. ${ }^{\dagger}$

\begin{tabular}{|c|c|c|c|c|c|c|}
\hline \multirow[b]{2}{*}{ Muscles } & \multicolumn{2}{|l|}{ Raw beef } & \multicolumn{2}{|l|}{ Cooked beef } & \multicolumn{2}{|l|}{ Cooked chicken } \\
\hline & mean $\pm S E$ & $\mathrm{~N}$ & mean $\pm \mathrm{SE}$ & $\mathbf{N}$ & mean $\pm \mathrm{SE}$ & $\mathrm{N}$ \\
\hline $\mathrm{ST}$ & $20.71 \pm 1.06$ & 63 & $15.07 \pm 1.16^{*}$ & 25 & $8.65 \pm 0.83^{* *}$ & 20 \\
\hline D'T & $25.22 \pm 1.38$ & 63 & $17.96 \pm 1.15^{*}$ & 25 & $11.91 \pm 1.12^{* *}$ & 20 \\
\hline $\mathrm{ZM}$ & $27.60 \pm 1.49$ & 63 & $22.14 \pm 1.74$ & 25 & $12.91 \pm 0.95^{* *}$ & 20 \\
\hline $\mathrm{DM}$ & $33.93 \pm 2.18$ & 63 & $26.76 \pm 1.91$ & 25 & $13.93 \pm 1.20^{* *}$ & 20 \\
\hline $\mathrm{SM}$ & $11.28 \pm 0.64$ & 63 & $7.59 \pm 0.65^{*}$ & 25 & $4.56 \pm 0.31^{* *}$ & 20 \\
\hline MPT & $31.50 \pm 2.39$ & 63 & $23.82 \pm 1.90^{*}$ & 25 & $18.98 \pm 1.70^{* *}$ & 20 \\
\hline
\end{tabular}

† Mean EMG spike amplitudes (in terms of $40 \mathrm{mV} /$ unit) during the same intervals as those in Table 6 for the working side adductors during a reduction sequence. (N equals the number of bites. Muscle abbreviations as in Figure 14.)

* Significantly different from raw beef at $\mathrm{P}<0.01$

**Significantly different from raw and cooked beef at $P<0.01$

TABLE 8. Correlation coefficients (r) comparing penetrometer values of mean compressive stresses for three distinct food types with four descriptors of EMG activity of the adductors of the working side. $\dagger$

\begin{tabular}{ccccc} 
Muscles & $\begin{array}{c}\text { Mean number } \\
\text { of intervals }\end{array}$ & $\begin{array}{c}\text { Mean number } \\
\text { of spikes }\end{array}$ & Mean amplitude & $\begin{array}{c}\text { Product of the } \\
\text { mean spike numbers } \\
\text { and amplitude }\end{array}$ \\
\hline ST & $0.998^{* *}$ & $0.991^{*}$ & $0.961^{*}$ & $0.999^{* *}$ \\
DT & $0.973^{*}$ & $0.996^{* *}$ & $0.982^{*}$ & $0.997^{* *}$ \\
ZM & 0.818 & 0.936 & 0.924 & 0.941 \\
DM & 0.939 & 0.797 & 0.920 & 0.911 \\
SM & 0.920 & $0.990^{* *}$ & $0.982^{*}$ & $0.998^{* *}$ \\
MPT & $0.965^{*}$ & $0.989^{*}$ & $0.993^{* *}$ & $0.996^{* *}$ \\
\hline
\end{tabular}

†The descriptors, each summed for $30.5 \mathrm{msec}$ intervals, are the mean number of intervals per bite, mean numbers of EMG spikes, the mean spike amplitudes, and the product of these means. (Muscle abbreviations as in Figure 14.)

* Significant correlation at $\mathrm{P}<0.05$.

**Significant correlation at $\mathrm{P}<0.01$. 
head and the tongue position the food both during ingestion and mastication and presumably add energy to the process.

In mastication, each opening movement of the mandible includes a simultaneous upward movement of the head. Thus, mouth opening involves not only depression of the mandible by action of the jaw opening muscles, but also elevation of the head by action of the nuchal musculature. Maximal closing acceleration of the mandible is coincident with a downward jerk of the head; the inertia of the bolus lets the mandibular teeth contact and penetrate it. Similarly, the tongue supports the food while the canines disengage. The tongue also repositions and maintains the food on the working side as the jaws close. Indeed, the tongue may provide sensory input on the location and the size of the food object when the mouth is open. At the end of a reduction sequence, the tongue is rubbed forward and back and cleans particles of food from the tooth row.

Vertical, anteroposterior, and horizontal movements of the head are also important during prey capture in wild felids (Biben, '79; Bourliere, '63; Eaton, '74; Ewer, '73; Hornocker, '70; Kruuk and Turner, '67; Schaller, '72; Turnbull-Kemp, '67). Downward movement of the head increases the penetrating force of the upper canines, while upward movement of the head might have a similar effect for the lower ones. Furthermore, movements of the head shift the dental arcades over uneven surfaces of the prey and allow meat to be torn (rather than bitten) from carcasses.

Forces transmitted to the prey via the teeth and acting between the mandible and skull must be balanced, but need not be produced by the masticatory musculature per se. Such forces may be generated by the nuchal as well as by axial and appendicular muscles. Cats often hold their prey by the forelimbs. Our feeding chamber effectively precludes this action; the limbs cannot reach the food and the chunks offered were relatively small. This suggests that the masticatory muscles were acting at much less than maximum capacity during the present experiments.

Previous experimental studies suggest that almost all mammals masticate by threedimensional movements of their mandibles (Gans et al., '78; Hiiemae, '78). Most of the species thus far studied masticate on one side at a time, although a few chew bilaterally (Herring and Scapino, '73; Weijs, '75; Weijs and Dantuma, '75). The main axis of each chewing cycle is vertical in cats; however, they, too, masticate on one side at a time, and their man- dibular cycles show both horizontal and anteroposterior deflections.

During reduction of foods that differ in texture, there is a consequent change in the pattern of mandibular movement (de Vree and Gans, '76; Gorniak, '77a; Gorniak and Gans, '77; Hiiemae, '78; Hiiemae et al., '78; Hiiemae and Thexton, '75; Thexton and Hiiemae, '75). Cats also show associated changes in the movement of the head. Apparently, mammals may modify the magnitude and direction of movements of the head as a whole to compensate for their having limited the range of man dibular movement in order to achieve particular occlusal patterns.

The pattern in which the mandible moves changes as the pieces of food become smaller during a reduction sequence; for instance, the cycles for raw and cooked beef gradually begin to resemble those for cooked chicken. These late cycles for raw and cooked beef agree with the "typical" mandibular movements illustrated by Hiiemae ('78; Fig. 4). The initial diversity of masticatory cycles emphasizes the importance of analyzing mandibular movements throughout a reduction sequence.

\section{The masticatory cycle}

As the jaws begin to separate, the mandibular canines appear to move almost vertically in lateral view; they then arc posteriorly as opening acceleration increases. Apparently, the mandibular condyles first rotate about their long axes, avoiding contact between the upper and lower canines, and then also translate anteriorly within the fossa after the canines separate and the mandible approaches the wide open position. Indeed, the loose capsule of the temporomandibular joint allows the condyle to slide anteriorly up on the low preglenoid ridge as gape increases.

Mastication in cats (Figs. 7 and 8), and apparently opossums and treeshrews (cf., Hiiemae, '78; Fig. 3) includes closing reversal movements during the opening phase. In cats, these coincide with a horizontal shift. The lower teeth then reengage the food at a site medial to that of the corresponding upper teeth. This medial penetration produces a force couple which moves the outer surface of the bolus laterally and its inner surface medially. Thus, these closing reversal movements change the area on the food contacted by the lower teeth and shift the portion previously penetrated toward the oral cavity.

When closing starts, the canines move upward and laterally toward the working side. 
This upward displacement is coincident with 1) rotation of the condyle of the working side about its long axis by contraction of the deep temporalis and zygomaticomandibularis of the working side, and 2) rotation of the condyle of the balancing side by contraction of the medial pterygoid and zygomaticomandibularis of the balancing side. Lateral displacement involves 1) retraction of the condyle of the working side by asymmetric firing of the deep temporalis of the working side and 2) a medial shift of the condyle of the balancing side induced by asymmetric activity of the medial pterygoid of the balancing side.

As closing proceeds, the mandible remains on the working side. The jaw is held laterally by high level activity of the zygomaticomandibularis and deep masseter of the working side. This activity pulls the jaw dorsally and toward the working side. Simultaneously, high level activity of the medial pterygoid of the balancing side pulls the lower jaw dorsally and away from the balancing side.

Close approximation of the working side carnassials and second premolars shears rather than bends the food. This shearing action occurs between 1) the paracone of the second maxillary premolar and the protoconid of the second mandibular premolar, 2) the paracone of the third maxillary premolar and the protoconid of the first mandibular molar, and 3 ) the metacone of the third maxillary premolar and the metaconid of the first mandibular molar. As the cusps of the lower carnassials slant anteriorly and while the cusps of the upper carnassials slant posteriorly, their contact zone shifts posteriorly with closing. The food object is then sliced between the teeth. The coincident downward shift of the head adds to the force of cutting.

Because of the differing textures of these food items, less force is required for teeth to penetrate and reduce cooked beef than raw beef (Table 1; Figs. 4 and 5). Consequently, the site at which the teeth contact cooked beef changes more often than does the contact site for raw beef; the lower number of reversals suggest $s$ that this is contacted during several successive bites (cf. Table 1, closing reversals during opening and food transfer). The initial texture of the food influences the number of chewing cycles, the frequency at which the site of active food reduction changes during a reduction sequence, and varied aspects of the electromyogram; however, the degree to which the food is reduced after each bite exerts the most critical influence on the several descriptors of mastication.
Contact between the teeth and food and coincident decrease of closing acceleration are accompanied by asymmetric muscular activity; however, the adductors on both sides are very active. Thus, penetration of the food by the carnassials involves upward forces generated by the adductors of both the working and the balancing side. Near the end of closure, as the lower jaw rotates about its long axis, the closing forces generated by the adductors of the balancing side are presumably transmitted through the symphysis menti to the teeth on the working side.

Near the end of the closing phase of a cycle, the canines approach each other, and the mandibular canine on the working side completes its excursion toward the midline. The digastric muscle of the balancing side is very active and introduces an additional retrusive force at the condyle of the balancing side, rotating the tip of the lower jaw toward the midline. Thus, differential activities of the adductors and digastrics induce transverse forces on the mandible and generate medial displacement. Apparently, the medial movement does not result from mechanical forces generated at the teeth.

Obviously, jaw closure is complex. Both asymmetric periods of activity of the deep temporales and medial pterygoids and the sequential action of the adductors generate and maintain lateral displacement coupled with the upward rotation of the mandible. Penetration of the food involves forces generated by the adductors of both sides. Near the end of closing, overlapping activities of adductors and abductors accompany movements of the lower jaws dorsally and medially.

\section{Muscular activity}

A recent review (Hiiemae, '78) emphasized that studies of mammalian mastication analyze muscular activity qualitatively and that this permits only the most generalized comparisons of interspecific activity. Direct computerized analysis of the electromyograms provides numerical descriptors of EMG activity and permits simple tests of their reproducibility. Table 2 documents that when several electrodes are implanted in a well-defined region of a muscle, the mean numbers of spikes and their mean spike amplitudes are reproducible not only among electrodes, but also among cats. This justifies a more detailed correlation among electrical events, mandibular movements, and nature of the food objects. It should now be possible to make quantitative interspecific comparisons, and the tabulation of 
our results presents a baseline subject to test by studies in other species.

Several studies in various mammals (Crompton et al.,'77; Gorniak, '77a; Kallen and Gans, '72), though not in pigs and rats (Herring, '76; Herring and Scapino, '73; Weijs and Dantuma, '75), show that high levels of unilateral activity from certain adductors indicate the side of active food reduction. In cats, the mean numbers of spikes and mean spike amplitudes for an entire reduction sequence are significantly greater for the adductors of the working than for the balancing side (Table 3 ). However, when muscular activity is compared separately during the start, middle, and end of a reduction sequence, one notes that differences in activity among the adductors of the working and of the balancing side are not always significant (Table 5), nor will the durations of activity per bite always differ significantly (Table 4). There remains some uncertainty about the outputs of EMG electrodes that are characterized only by standardization and automated analysis. It may well be that differences in EMG signals are functionally significant to the animal before they show statistical significance.

Movements of the mandible are affected by the type of food being reduced; however, only a few reports relate this observation to changes in muscular activity (Thexton and Hiiemae, '75). The present results indicate that the periods during which the adductors in cats are active per bite and the activity levels of these muscles are influenced by the consistency of the food, and that the activity levels apparently indicate the relative magnitude of cutting and crushing forces involved during reduction (Table 8). The activities of the digastrics and lateral pterygoids more closely reflect changes in the vertical and lateral displacements of the mandible-i.e., changes in the dimensions of the bolus-than of the consistency of the food.

The significant positive correlation between the mean numbers of spikes and the mean spike amplitudes of all the adductors suggests that either mean (or their products) adequately describes changes in activity, both those accompanying shifts among foods with differing texture and those during a reduction sequence. However, the number of spikes for each sampled interval (one film frame) for each bite shows substantial variability and this variability precludes drawing any conclusions until further tests are completed. Although the spike amplitudes for each sampled interval more consistently reflect the relative magnitude of muscular activity, it is now necessary to test for correlation among descriptors, such as the number of spikes, the spike amplitude profile and the number-amplitude products for single intervals, and for correlation among local characteristics of the muscle, such as fiber area, fiber arrangement, fiber histochemistry, tetanic tension, and fatigability (cf. Gorniak et al., '79).

Table 8 shows higher correlation coefficients for the products of the mean numbers of spikes times the mean spike amplitudes than for either mean separately. Thus, the product of the means (and the mean of the products of the number of spikes times spike amplitude for each sampled interval) may be adequate descriptors to correlate muscular activities with compressive stress as determined from penetrometer readings.

\section{ACKNOWLEDGMENTS}

We thank J. Beach and T. Harkaway for aid in developing the computer hardware and programs, and B.D. Clark, A.S. Gaunt, F.C. Kallen, and T.C. Scanlon for their trenchant comments on the manuscript. W. Bartels and C. Childress discovered the error in the scales of earlier acceration graphs. Illustrations were prepared by J. Daugherty and R. Hebeler.

This study was supported by NIH 5 F32 Am05368, NSF DEB 77-02605 and the Office of the Vice-President for Research, The University of Michigan.

Parts of this study were reported at meetings of the American Association of Anatomists and the American Society of Zoologists (Gorniak, '77b; Gorniak and Gans, '77).

\section{LITERATURE CITED}

Arendsen de Wolff-Exalto, E. (1951) On differences in the lower jaw of animalivorous and herbivorous mammals. Proc. K. Ned. Akad. Wet. (C), 54:237-246, 405-410.

Becht, G. (1953) Comparative biologic-anatomical re searches on mastication in some mammals. Proc. K. Ned. Akad. Wet. (C), 56:508-527.

Biben, M. (1979) Predation and predatory play behavior of domestic cats. Anim. Behav., 27:81-94.

Bourlière, F. (1963) Specific feeding habits of African carnivores. Afr. Wildl., 17:21-27.

Brodie, A.G. (1934) The significance of tooth form. Angle Orthod., 4:335-350.

Crompton, A.W., A.J. Thexton, P. Parker, and K. Hiiemae (1977) The activity of the jaw and hyoid musculature in the Virginia opossum, Didelphis virginiana. In: The Biology of Marsupials. B. Stonehouse and G. Gimore, eds. MacMillan, New York, pp. 287-305.

Crouch, J.E. (1969) Text-Atlas of Cat Anatomy. Lea \& Febiger, Philadelphia.

de Vree, F., and C. Gans (1976) Mastication in pygmy goats, Capra hircus. Ann Soc. Zool. Belge, 105(3-4):255-306.

Eaton, R.L. (1974) The Cheetah: The Biology, Ecology, and Behavior of an Endangered Species. Van Nostrand Reinhold Co., New York. pp. 129-145. 
Ewer, R.F. (1973) The Carnivores. Cornell University, Ithaca, NY

Gadd, C.W., F.J. Peterson, and W.A. Lange (1967) Strength of skin and its measurement with special application to trauma. ASME Biomechanics Monogr., pp. 184-191.

Gans, C., F. de Vree, and G.C. Gorniak (1978) Analysis of mammalian masticatory mechanisms: Progress and problems. Anat. Histol. Embryol., 7:226-244.

Gaspard, M. (1971) Anatomie comparative et functionnelle de la musculature masticatrice chez les carnivores. Mem. Mus. Nat. Hist. Nat. (Paris) N.S., Ser. A., Zool., 63:1-207.

Gorniak, G.C. (1977a) Feeding in golden hamsters, Mesocricetus auratus. J. Morphol., 154:427-458.

Gorniak, G.C. (1977b) Mastication in the domestic cat, Felis domestica, Anat. Rec., 187:591 (abstr).

Gorniak, G.C., and C. Gans (1977) Mastication of varying food types in cats, Felis domestica. Am. Zool., 17:886 (abstr).

Gorniak, G.C., C. Gans, and J.A. Faulkner (1979) Muscle fiber regeneration after transplantation: Prediction of structure and physiology from electromyograms. Science, 204: 1085-1087.

Herring, S.W. (1976) The dynamics of mastication in pigs. Arch. Oral Biol., 21:473-480.

Herring, S.W., and R.P. Scapino (1973) Physiology of feeding in miniature pigs. J. Morphol., 141:427-460.

Herring, S.W., A.F. Grimm, and B.R. Grimm (1979) Functional heterogeneity in a multipinnate muscle. Am. J Anat., 154:563-597.

Hiiemae, K.M. (1978) Mammalian mastication: A review of the activity of the jaw muscles and movements they produce. In: Development, Function, and Evolution of Teeth. P.M. Butler and K.A. Joysey, eds., Academic Press, London, pp. 359-398.

Hiiemae, K.M., A.J. Thexton, and A.W. Crompton (1978) Intra-oral food transport: The fundamental mechanism of feeding. In: Muscle Adaptation in the Craniofacial Region. D.S. Carlson and J. A. McNamara, Jr., eds. Mono. 8, Center for Human Growth and Development, The University of Michigan, pp. 181-208.

Hiiemae, K.M., and A.J. Thexton (1975) Consistency and bite size as regulators of mastication in cats. IADR Abstracts 54:L94 (abstr).

Hnik, P., S. Kasicki, Z. Afelt, R. Vejsada, and I. Krekule (1978) Chronic polyelectromyography in awake, unrestrained animals. Physiol. Bohemoslov, 27:485-492.

Hornocker, M. (1970) An analysis of mountain lion predation upon mule deer and elk in the Idaho primitive area. Wildl. Monogr. No. 21, Wildl. Soc., pp. 6-36.

Kallen, F.C., and C. Gans (1972) Mastication in the little brown bat, Myotis lucifugus. J. Morphol., 136:385-420.

Kraus, B.S., R.E. Jordon, and L. Abrams (1969) Dental Anatomy and Occlusion. Williams \& Wilkins, Baltimore.

Kruuk, H., and M. Turner (1967) Comparative notes on predation by lion, leopard, cheetah, and wild dog in the
Serengeti area, East Africa. Mammalia, 31(1):1-27.

Kumur, Y.P., D.S. Mishra, and P. Prakash (1978) Morphological changes in cooked longissimus dorsi muscle of pig, buffalo, sheep, goat, and poultry. Anat. Anz., 143:145-151.

Lister, D. (1970) The physiology of animals and the use of their muscles for food. In: The Physiology and Biochemistry of Muscle as Food. E.J. Brisky, R.G. Cassens, and B.B. Marsh, eds. Univ. of Wisconsin Press, Madison, Vol. 2, pp. 705-734.

Mohsein, N.N. (1970) Physical Properties of Plant and Animal Materials. Gordon and Breach Sci. Publ., London, pp. 309-382.

Peyer, B. (1968) Comparative Odontology. R. Zangerl, trans. and ed. University of Chicago Press, Chicago.

Reighard, J., and H.S. Jennings (1935) Anatomy of the Cat. Henry Holt and Co., New York.

Ryder, J.A. (1878) On the mechanical genesis of tooth-forms. Proc. Acad. Nat. Sci. (Phila.) 79:45-80.

Schaller, G.B. (1972) The Serengeti Lion. University of Chicago Press, Chicago.

Schumacher, G.H. (1961) Funktionelle Morphologie der Kaumuskulatur. Gustav Fischer, Jena.

Simpson, G.G., A. Roe, and R.C. Lewontin (1960) Quantitative Zoology. 2nd ed. Harcourt, Brace and World Co., New York.

Smith, J.M., and R.J.G. Savage (1959) The mechanics of mammalian jaws. School Sci. Rev., 40:289-301.

Taylor, A. (1976) Fiber types in the muscles of mastication. In: Mastication. D.J. Anderson and B. Matthews, eds. John Wright, Bristol, pp. 16-34.

Thexton, A.J. (1976) To what extent is mastication programmed and independent of peripheral feed-back? In: Mastication. D.J. Anderson, and B. Matthews, eds. John Wright, Bristol, pp. 213-219.

Thexton, A.J., and K.M. Hiiemae (1975) Masticatory electromyographic activity as a function of food consistency. IADR Abstracts 54:L95 (abstr).

Tuomy, J.M., R.J. Lechnir, and T. Miller (1963) Effect of cooking temperature and time on the tenderness of beef. Food Technol., 17:1457.

Turnbull, W.D. (1970) Mammalian masticatory apparatus. Fieldiana: Geology, 18:149-356.

Turnbull-Kemp, P. (1967) The Leopard. Howard Timmins, Cape Town. pp. 111-114

van der Klaauw, C.J. (1952) Functional components of the skull. Arch. Neerl. Zool., 9:369-559.

Vaughan, T.A. (1972) Mammalogy. W.B. Saunders Co., Philadelphia.

Weijs, W.A. (1975) Mandibular movements of the albino rat during feeding. J. Morphol,, 145: 107-124.

Weijs, W.A., and R. Dantuma (1975) Electromyography and mechanics of mastication in the albino rat. J. Morphol., 146:1-34

Young, J.Z. (1962) The Life of Vertebrates. Oxford University Press, New York. 